\title{
Targeting VE-PTP activates TIE2 and stabilizes the ocular vasculature
}

\author{
Jikui Shen, ${ }^{1}$ Maike Frye, ${ }^{2}$ Bonnie L. Lee, ${ }^{3}$ Jessica L. Reinardy, ${ }^{3}$ Joseph M. McClung, ${ }^{3}$ Kun Ding, ${ }^{1}$ Masashi Kojima, ${ }^{1}$ Huiming Xia, ${ }^{1}$ \\ Christopher Seidel, ${ }^{1}$ Raquel Lima e Silva, ${ }^{1}$ Aling Dong, ${ }^{1}$ Sean F. Hackett, ${ }^{1}$ Jiangxia Wang, ${ }^{1}$ Brian W. Howard, ${ }^{4}$ Dietmar Vestweber, ${ }^{2}$ \\ Christopher D. Kontos, ${ }^{3}$ Kevin G. Peters, ${ }^{5}$ and Peter A. Campochiaro ${ }^{1}$

\begin{abstract}
'Departments of Ophthalmology and Neuroscience, Johns Hopkins University School of Medicine, Baltimore, Maryland, USA. ²Department of Cell Biology, Max Planck Institute for Molecular Biomedicine, Muenster, Germany. ${ }^{3}$ Department of Medicine, Division of Cardiology, Duke University Medical Center, Durham, North Carolina, USA. ${ }^{4}$ Procter \& Camble, Cincinnati, Ohio, USA. ${ }^{5}$ Aerpio Therapeutics, Cincinnati, Ohio, USA.
\end{abstract}

\begin{abstract}
Retinal and choroidal neovascularization (NV) and vascular leakage contribute to visual impairment in several common ocular diseases. The angiopoietin/TIE2 (ANG/TIE2) pathway maintains vascular integrity, and negative regulators of this pathway are potential therapeutic targets for these diseases. Here, we demonstrated that vascular endothelial-protein tyrosine phosphatase (VE-PTP), which negatively regulates TIE2 activation, is upregulated in hypoxic vascular endothelial cells, particularly in retinal NV. Intraocular injection of an anti-VE-PTP antibody previously shown to activate TIE2 suppressed ocular NV. Furthermore, a small-molecule inhibitor of VE-PTP catalytic activity (AKB-9778) activated TIE2, enhanced ANG1induced TIE2 activation, and stimulated phosphorylation of signaling molecules in the TIE2 pathway, including AKT, eNOS, and ERK. In mouse models of neovascular age-related macular degeneration, AKB-9778 induced phosphorylation of TIE2 and strongly suppressed NV. Ischemia-induced retinal NV, which is relevant to diabetic retinopathy, was accentuated by the induction of ANG2 but inhibited by AKB-9778, even in the presence of high levels of ANC2. AKB-9778 also blocked VECFinduced leakage from dermal and retinal vessels and prevented exudative retinal detachments in double-transgenic mice with high expression of VEGF in photoreceptors. These data support targeting VE-PTP to stabilize retinal and choroidal blood vessels and suggest that this strategy has potential for patients with a wide variety of retinal and choroidal vascular diseases
\end{abstract}

\section{Introduction}

Over the past several years, there has been considerable progress in elucidating molecular mechanisms involved in pathologic angiogenesis and excessive vascular leakage, and it is well established that VEGF plays an important role $(1,2)$. This has provided benefits in oncology, but the major benefits have come in the treatment of eye diseases. Intraocular injections of VEGF-binding proteins have shown efficacy in patients with neovascular age-related macular degeneration (AMD), but sustained benefit often requires frequent injections, despite which some patients experience persistent leakage and reduced vision (3). VEGF also plays a central role in ischemic retinopathies, including diabetic retinopathy and retinal vein occlusions, and VEGF antagonists suppress retinal neovascularization (NV), reduce macular edema, and provide visual gains (4-8); however, frequent injections for many years are needed, and some patients respond poorly or incompletely (9-11). Thus, although

\footnotetext{
Note regarding evaluation of this manuscript: Manuscripts authored by scientists associated with Duke University, The University of North Carolina at Chapel Hill, Duke-NUS, and the Sanford-Burnham Medical Research Institute are handled not by members of the editorial board but rather by the science editors, who consult with selected external editors and reviewers

Conflict of interest: Dietmar Vestweber, Christopher Kontos, and Peter Campochiaro serve on the Scientific Advisory Board for Aerpio Therapeutics. Kevin Peters is an employee of Aerpio Therapeutics.

Submitted: December 2, 2013; Accepted: July 24, 2014

Reference information: J Clin Invest. 2014;124(10):4564-4576. doi:10.1172/JCI74527.
}

VEGF antagonists have substantially improved the lives of patients with ocular diseases complicated by NV or excessive vascular leakage, there is still considerable unmet medical need.

One way to address this unmet need is to target other relevant signaling pathways, such as that mediated by the TIE2 tyrosine kinase, a receptor for the angiopoietin (ANG) family of secreted proteins. ANG2, the endogenous, context-dependent inhibitor of TIE2 (12), is necessary for retinal vascular development and is expressed in association with retinal or choroidal NV (13-15). Highlevel expression of VEGF at the inner surface of the retina does not cause retinal NV unless it is accompanied by increased expression of ANG2 (16). Doxycycline-induced (Dox-induced) expression of ANG2 in double-transgenic opsin-rtTA Tet-Ang2 mice (referred to hereafter as Tet-opsin-Ang2 mice) stimulates NV when VEGF levels are high and causes regression of NV when VEGF levels are low (17). In contrast, expression of ANG1, the endogenous agonist for TIE2 (18), is not context dependent and suppresses NV and leakage in the eye $(19,20)$. These dramatic results suggest that ANG1 or another TIE2 agonist could be useful in ocular diseases complicated by NV and/or excessive vascular leakage, but there has been little progress translating them into the clinic.

Regulation of TIE2 also occurs through the endothelial cellspecific receptor tyrosine phosphatase human protein tyrosine phosphatase $\beta$ (HPTP- $\beta$, gene symbol PTPRB) (21). The mouse ortholog of HРТP- $\beta$ was named vascular endothelial protein 
Table 1. $\mathrm{IC}_{50}(\mathrm{nM})$ for $A K B-9778$ versus a panel of diverse phosphatase enzymes ${ }^{\mathrm{A}}$

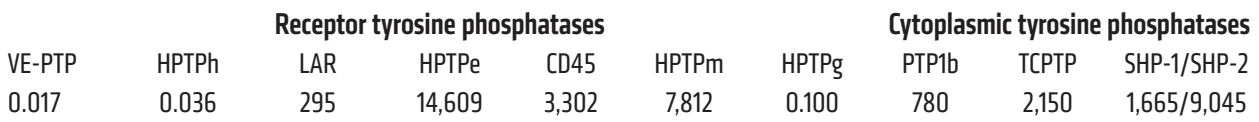

${ }^{A} C_{50} S(n M)$ for a variety of additional phosphatases were 20,000 to $>100,000$ : cytoplasmic tyrosine phosphatases HCPTPA and PRL3; dual-specificity phosphatases MKP-1 and VHR; serine/threonine phosphatases ALP and PP1g.

tyrosine phosphatase (VE-PTP) (22). To avoid confusion, we refer to both as VE-PTP, which emphasizes the critical characteristic of endothelial cell expression. Mice lacking VE-PTP die at E10 with severe defects in vascular remodeling and maturation of developing vasculature $(23,24)$. In cultured endothelial cells, hypoxia increases VE-PTP mRNA and decreases TIE2 activation, while silencing of VE-PTP enhances basal and ANG1-mediated TIE2 phosphorylation, downstream signaling, and cellular responses $(25,26)$. VE-PTP physically associates with TIE2, and injection of an antibody directed against its extracellular domain dissociates VE-PTP from TIE2, resulting in TIE2 activation and downstream signaling (26). In this study, using 2 independent approaches, we explored the potential benefit of targeting VE-PTP for treatment of ocular NV and excessive vascular permeability.

\section{Results}

$V E-P T P$ is upregulated in hypoxic endothelial cells in vitro and in vivo. Compared with HUVECs kept in 21\% oxygen, those kept in 5\% oxygen showed a substantial increase in VE-PTP protein (Figure 1A). To determine whether VE-PTP is also upregulated in hypoxic endothelial cells in vivo, we used a model of oxygen-induced ischemic retinopathy in which mice have areas of ischemic retina and develop NV by P17 (27). Flat mounts of retinas from P17 mice with ischemic retinopathy showed strong staining for VE-PTP in the NV on the surface of the retina (Figure 1B) and faint staining of some of the retinal vessels in the background (Figure 1B, right panel, arrowheads). We observed no staining in the absence of primary antibody (Figure 1C) and no staining in nonischemic retinas from control mice (Figure 1D). Thus, VE-PTP expression is upregulated by hypoxia and is markedly increased in endothelial cells participating in ischemia-driven retinal NV.

Specific blockade of VE-PTP suppresses retinal and subretinal NV. We used a monoclonal antibody against the extracellular domain of VE-PTP previously shown to activate TIE2 (25) to explore the effects of targeting VE-PTP in mouse models of NV. At P12, mice with ischemic retinopathy were administered an intravitreous injection of $0.1,0.5$, or $2 \mu \mathrm{g}$ anti-VE-PTP antibody or $2 \mu \mathrm{g}$ control IgG. At P17, we observed a significant reduction in the area of retinal NV in eyes treated with $2 \mu \mathrm{g}$ anti-VE-PTP antibody, but not in those injected with 0.1 or $0.5 \mu \mathrm{g}$ (Figure 1E).

Subretinal NV occurs in patients with neovascular AMD and can originate either from the choroid (choroidal NV) or from the deep capillary bed of the retina, termed retinal angiomatous proliferation (RAP) (28). Choroidal NV is modeled by laser-induced rupture of Bruch's membrane (29), and Rho-VEGF-transgenic mice provide a model of RAP $(30,31)$. These models have shown good ability to predict drug effects in patients with neovascular AMD $(32,33)$. At P15, Rho-VEGF-transgenic mice were given an intravitreous injection of 0.5 or $2 \mu \mathrm{g}$ anti-VE-PTP in 1 eye and a corresponding amount of control IgG in the fellow eye. At P21, there was significantly less subretinal NV in eyes treated with 0.5 or $2 \mu \mathrm{g}$ anti-VE-PTP compared with fellow eyes treated with control IgG (Figure 1F). Mice with laser-induced rupture of Bruch's membrane had intravitreous injection of 0.1, 0.5, or $2 \mu \mathrm{g}$ anti-VE-PTP in 1 eye and $2 \mu \mathrm{g}$ control IgG or no injection in the fellow eye. After 7 days, there was significantly less choroidal NV in eyes treated with $2 \mu \mathrm{g}$ antiVE-PTP compared with fellow eyes treated with control IgG (Figure 1G). These data support an important role for VE-PTP in the pathogenesis of retinal and subretinal NV.

AKB-9778, a potent and selective small-molecule inhibitor of the catalytic activity of VE-PTP, promotes TIE2 activation and downstream signaling. To further probe the potential of targeting VE-PTP for the treatment of ocular NV, we used the newly developed, potent and selective inhibitor of VE-PTP catalytic activity AKB-9778 (Figure 2). The phenylsulfamic acid moiety acts as a general phosphotyrosine mimetic "warhead" $(34,35)$, and surrounding moieties were optimized as part of an extensive structure-based drug design program $(35,36)$. AKB-9778 inhibits the phosphatase activity of VE-PTP with an $\mathrm{IC}_{50}$ of $17 \mathrm{pM}$, while inhibiting the structurally related phosphatase PTP1B with an $\mathrm{IC}_{50}$ of $780 \mathrm{nM}$ (Table 1). AKB-9778 shows excellent selectivity for VE-PTP versus a variety of phosphatases, with the exception of HPTP $\left(\mathrm{IC}_{50}=36 \mathrm{pM}\right)$ and HPTP $\gamma$ $\left(\mathrm{IC}_{50}=100 \mathrm{pM}\right)$. Substrate velocity curves and Lineweaver-Burk plots indicated that AKB-9778 is a competitive inhibitor of VE-PTP phosphatase activity (data not shown).

To determine the effect on TIE2 activation, HUVECs were incubated with AKB-9778 in the absence or presence of ANG1 or ANG2. Tyrosine phosphorylation of TIE2 was undetectable in untreated HUVECs, but incubation with AKB-9778 at concentrations ranging from 0.17 to $50 \mu \mathrm{M}$ resulted in concentrationdependent phosphorylation of TIE2 (Figure 3A) and downstream components of the TIE2 signaling pathway, including eNOS, AKT, and ERK (Figure 3B). Densitometric measurements are shown in Supplemental Figure 1 (supplemental material available online with this article; doi:10.1172/JCI74527DS1). We found that AKB-9778 induced detectable TIE2 activation at the lowest concentration tested $(0.17 \mu \mathrm{M}$, best seen for p-AKT long exposure; Figure 3B). Phosphorylation of TIE2, eNOS, AKT, and ERK induced by $1.7 \mu \mathrm{M}$ AKB-9778 was similar to that induced by $500 \mathrm{ng} / \mathrm{ml}$ ANG1 alone and was markedly enhanced by coincubation of ANG1 with AKB-9778 (Figure 3, A and B). We found that ANG2 alone $(500 \mathrm{ng} / \mathrm{ml})$ induced no detectable phosphorylation of TIE2 or downstream molecules, but TIE2 phosphorylation after coincubation with ANG2 and AKB-9778 was only slightly less than that seen after coincubation with ANG1 and AKB-9778. To definitively test whether the effects of AKB-9778 are mediated through TIE2, we used a human TIE2-specific shRNA to knock down TIE2 in an immortalized endothelial cell line (EC-RF24) and found that the effects of AKB-9778 on signaling by both ANG1 and ANG2 were abrogated (Figure 3C). We 


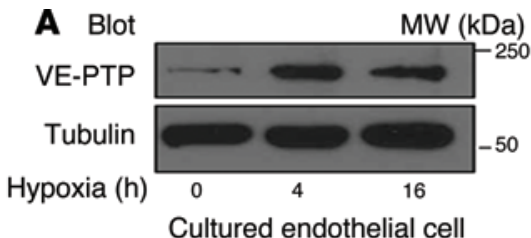

C
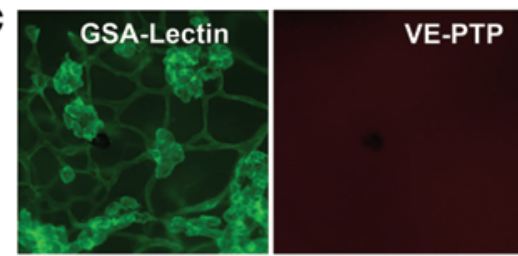

Antibody control
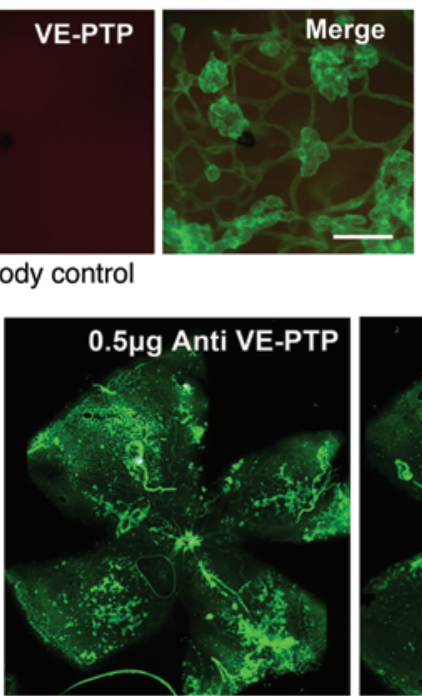

Ischemic retinopathy
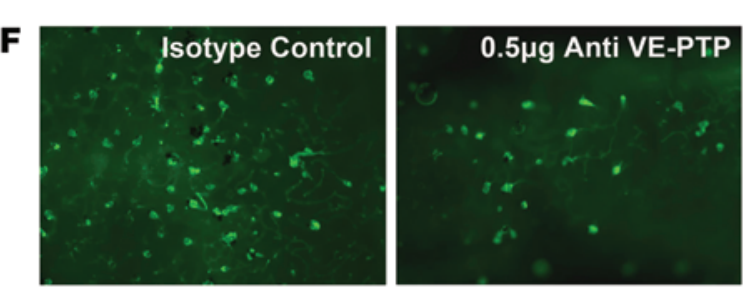

Rho/VEGF transgenics
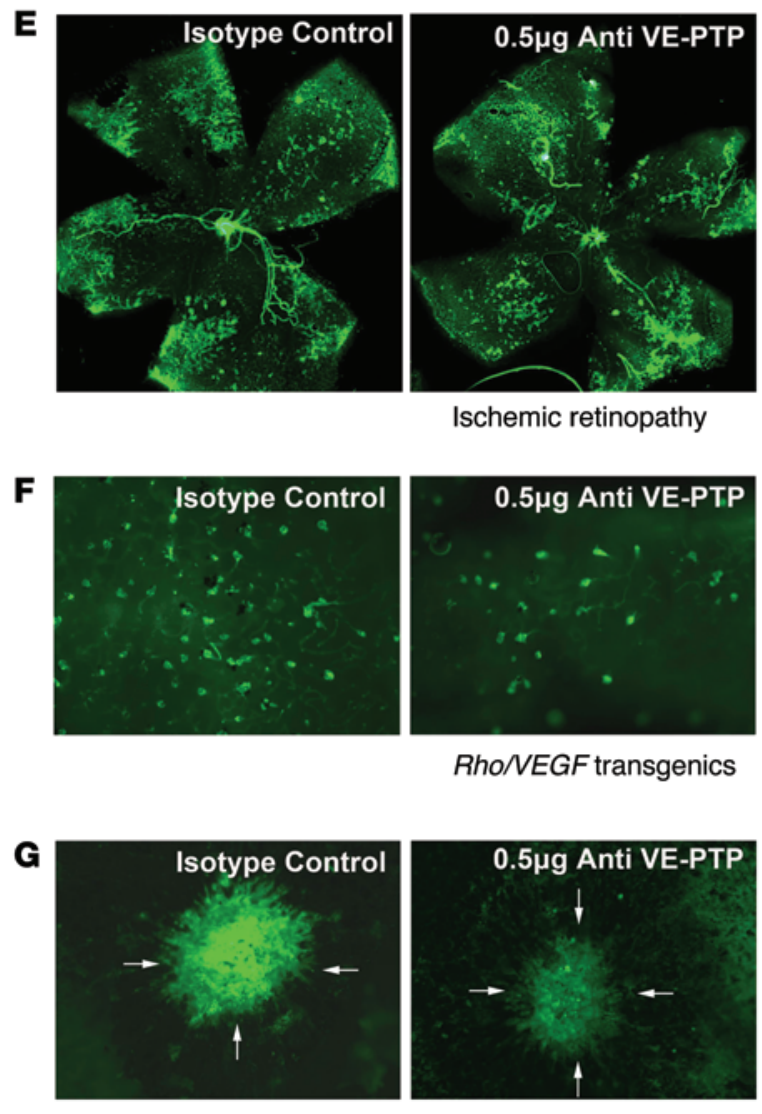

B
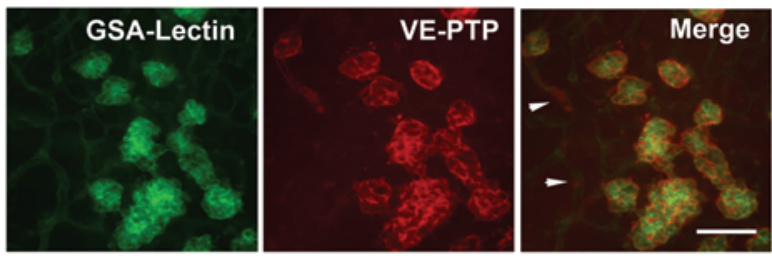

Ischemic retinopathy
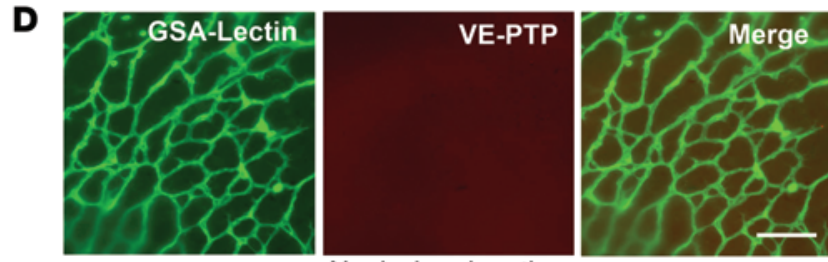

Nonischemic retina
Choroidal NV
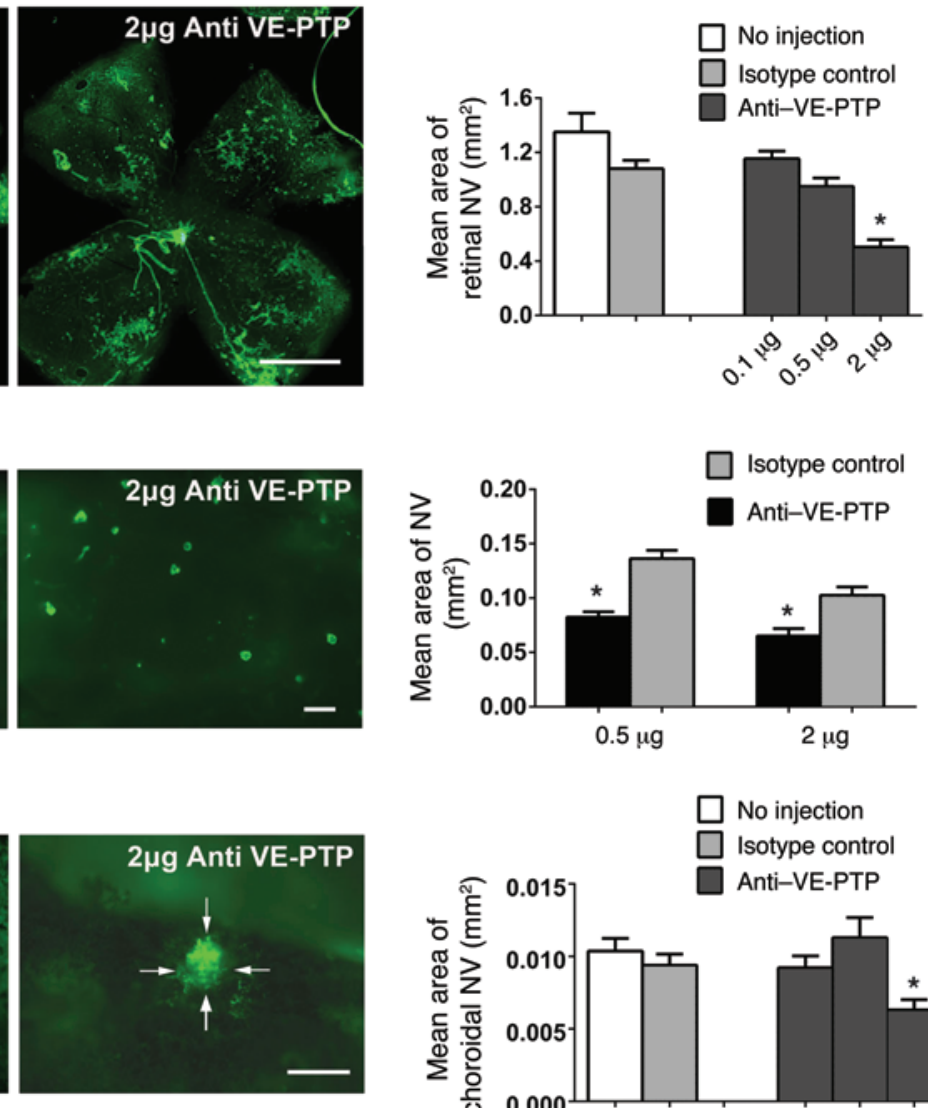
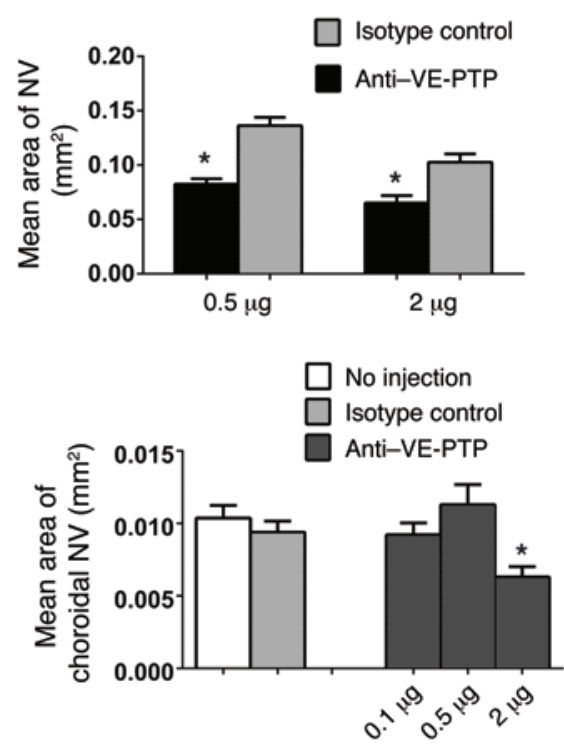

Figure 1. VE-PTP is upregulated in hypoxic endothelial cells and plays an important role in ocular NV. (A) After incubation in $5 \%$ oxygen for 0,4 , or 16 hours, hypoxic HUVECs showed an increase in VE-PTP. (B) GSA lectin-stained retinal NV in P17 mice with ischemic retinopathy stained for VE-PTP, with faint staining of preexistent retinal vessels (arrowheads). Scale bar: $100 \mu \mathrm{m}$. (C) Elimination of primary antibody eliminated staining. Scale bar: $100 \mu \mathrm{m}$. (D) Nonischemic retinas at P17 showed normal CSA-stained vessels, no NV, and no VE-PTP staining. Scale bar: $100 \mu \mathrm{m}$. (E) At P12, mice with ischemic retinopathy were administered an intravitreous injection of $0.1,0.5$, or $2 \mu \mathrm{g}$ anti-VE-PTP or $2 \mu \mathrm{g}$ IgG isotype control ( $n \geq 12$ for each). At P17, there was extensive GSA-stained retinal NV in control IgG-injected eyes and significantly less detected in eyes injected with $2 \mu$ g anti-VE-PTP. ${ }^{*} P<0.001$ for comparison with IgG control by 1-way ANOVA with Bonferroni's correction. Scale bar: $500 \mu \mathrm{m}$. (F) At P15, Rho-VEGF-transgenic mice were given an intravitreous injection of 0.5 or $2 \mu \mathrm{g}$ anti-VE-PTP in 1 eye and a corresponding dose of control IgG in the fellow eye ( $n=6$ for each). At P21, there was significantly less GSA-stained subretinal NV in eyes injected with 0.5 or $2 \mu \mathrm{g}$ anti-VE-PTP than in control IgG-injected eyes. ${ }^{*} P=0.01$ by unpaired $t$ test for comparison with IgC control fellow eyes. Scale bar: $100 \mu \mathrm{m}$. (C) Intravitreous injection of $2 \mu \mathrm{g}$ anti-VE-PTP significantly reduced the area of choroidal NV at Bruch's membrane rupture sites compared with control IgG. ${ }^{*} P<0.001$ by 1-way ANOVA with Bonferroni's correction. Scale bar: $100 \mu \mathrm{m}$. MW, molecular weight. 


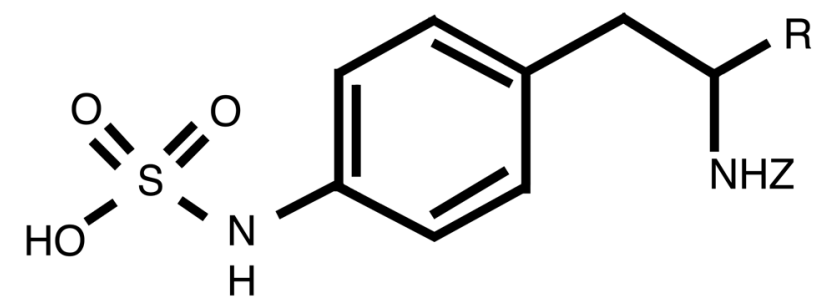

Figure 2. The core structure of AKB-9778 (p-substituted phenylsulfamic acid).

observed no effect of AKB-9778 on phosphorylation of VEGFR2, either alone or in combination with VEGF, demonstrating selectivity of VE-PTP inhibition for TIE2 activation (Figure 3D).

AKB-9778 promotes phosphorylation of TIE2 in retinal endothelial cells in vivo. At P21, Rho-VEGF-transgenic mice were administered a s.c. injection of vehicle or $20 \mathrm{mg} / \mathrm{kg}$ AKB-9778, and after 12 hours, we observed that new vessels in vehicle-treated mice stained for TIE2, but not p-TIE2, whereas new vessels in AKB-9778treated mice stained for both TIE2 and p-TIE2 (Figure 4A). Likewise, in vehicle-treated mice with ischemic retinopathy, we found that retinal NV stained for TIE2 and not p-TIE2, but treatment with AKB-9778 resulted in strong staining for p-TIE2 (Figure 4B). Similar to the effect of AKB-9778, intraocular injection of $500 \mathrm{ng}$ ANG1 caused staining for p-TIE2 in retinal NV (Figure 4C).

AKB-9778 suppresses subretinal NV. Subcutaneous injections of 10 or $20 \mathrm{mg} / \mathrm{kg}$ AKB-9778 twice daily for 7 days after rupture of Bruch's membrane caused a significant reduction in the mean area of choroidal NV compared with that observed with injection of vehicle (Figure 5A). In Rho-VEGF mice, s.c. injections of $10 \mathrm{mg} / \mathrm{kg}$ between P15 and P21 significantly reduced the area of subretinal NV (Figure 5B). Intraocular injection of AKB-9778 also suppressed choroidal and subretinal NV (Figure 5, C and D). Compared with fellow eyes injected with vehicle, eyes given an intraocular injection of 3 or $5 \mu \mathrm{g}$, but not $1 \mu \mathrm{g}$, AKB-9778 had significantly less choroidal NV at Bruch's membrane rupture sites (Figure 5C). A single intraocular injection of $5 \mu \mathrm{g}$ AKB-9778 at P15 into Rho-VEGF mice reduced the mean area of subretinal $\mathrm{NV}$ compared with that observed in control eyes injected with vehicle (Figure 5D). In an independent experiment, mice had rupture of Bruch's membrane followed by an intraocular injection of $40 \mu \mathrm{g}$ aflibercept, a VEGF trap, or vehicle and s.c. injections of $20 \mathrm{mg} / \mathrm{kg}$ AKB- 9778 or vehicle twice daily. After 7 days, the mean area of choroidal NV in mice treated with an intraocular injection of aflibercept alone or a s.c. injection of AKB-9778 alone was significantly smaller than that seen in mice that received 2 control injections (Figure 5E). Mice treated with both an intraocular injection of aflibercept and s.c. injections of AKB-9778 had significantly less choroidal NV than did mice treated with either agent alone (Figure 5E).

$A K B-9778$ suppresses ischemia-induced retinal $N V$ in the presence of high levels of ANG2. Tet-opsin-Ang2 mice have Dox-inducible expression of ANG2 in the retina, and when oxygen-induced ischemic retinopathy is induced in these mice, they develop much more retinal NV when treated with Dox than they do when untreated (17). We used these mice to determine the effects of AKB-9778 on ischemia-induced retinal NV in the setting of high ANG2 levels. Dox-treated Tet-opsin-Ang2 mice with ischemic retinopathy developed extensive NV by P17 (Figure 6A), while Dox-treated mice given a single intraocular injection of $5 \mu \mathrm{g}$ AKB-9778 developed significantly less NV (Figure 6, B and E). Without induction of ANG2, Tet-opsin-Ang2 mice developed mild ischemia-induced retinal NV (Figure 6C), which appeared less marked in eyes injected with $3 \mu \mathrm{g}$ AKB-9778, but the difference was not statistically significant (Figure 6, D and E). As previously demonstrated (17), induced high expression of ANG2 stimulated retinal NV in mice with ischemic retinopathy; however, despite high levels of ANG2 and retinal ischemia, AKB-9778 significantly suppressed NV (Figure 6E). Notably, these in vivo findings are consistent with the effects of AKB-9778 we observed in hypoxic endothelial cells in vitro. After incubation of HUVECs in $5 \%$ oxygen for 4 or 16 hours, conditions that upregulate VE-PTP (Figure 1A), ANG1-induced TIE2 activation and downstream signaling were markedly blunted (Figure 6, $\mathrm{F}$ and $\mathrm{G}$ ). However, AKB-9778 restored TIE2 activation (Figure 6F) and downstream signaling (Figure 6G) in hypoxic endothelial cells, even in the presence of exogenous ANG2.

AKB-9778 blocks VEGF- and histamine-mediated vascular leakage. Having shown that AKB-9778 reduced NV in multiple models, we next explored its effects on excessive endothelial cell permeability and vascular leakage. Confluent HUVECs grown on permeable membranes develop tight junctions and impede the passage of fluorescently labeled dextran to an adjacent chamber. The addition of VEGF to the upper chambers significantly increased FITCdextran in the lower chambers, and this was blocked by AKB-9778 (Figure 7A). Transgenic expression of ANG1 in the skin has been shown to reduce vascular permeability induced by various proinflammatory factors (37). The Miles assay is commonly used to test the effect of agents on the permeability of dermal and s.c. blood vessels. To assess the antipermeability effects of AKB-9778, mice received 2 i.v. doses of AKB- $9778(16 \mathrm{mg} / \mathrm{kg})$ or vehicle, 1 injection 5 hours before and 1 immediately prior to the start of the assay. All mice then received an i.v. injection of Evans blue dye and 10 minutes later were challenged with intradermal injections of PBS, histamine, or VEGF. We found that both histamine and VEGF induced marked increases in vascular permeability, which was significantly reduced by AKB-9778 (Figure 7B). The beneficial effects on vascular permeability correlated with increased TIE2 phosphorylation in the lung tissue of AKB-9778-treated mice compared with that observed in vehicle-treated animals (Figure 7C).

Although AKB-9778 has excellent selectivity, it is only 2-fold more potent in inhibiting the activity of VE-PTP than the related phosphatase HPTP $\eta$ (DEP-1). Miles assays as described above were performed in parallel in DEP-1-KO and WT mice. We observed no difference in AKB-9778-mediated suppression of VEGF- and histamine-induced leakage in DEP-1-KO mice compared with that in WT mice, indicating that inhibition of DEP-1 does not contribute to the antipermeability activity of AKB-9778 (Supplemental Figure 2A). Treatment with AKB-9778 stimulated increased phosphorylation of TIE2 in the lungs of DEP-1-KO mice at a level similar to that seen in WT mice (Supplemental Figure 2B).

$A K B-9778$ reduces VEGF-induced leakage from retinal vessels and NV. In Rho-VEGF-transgenic mice, overexpression of VEGF in the retina causes leakage of plasma from preexistent retinal 

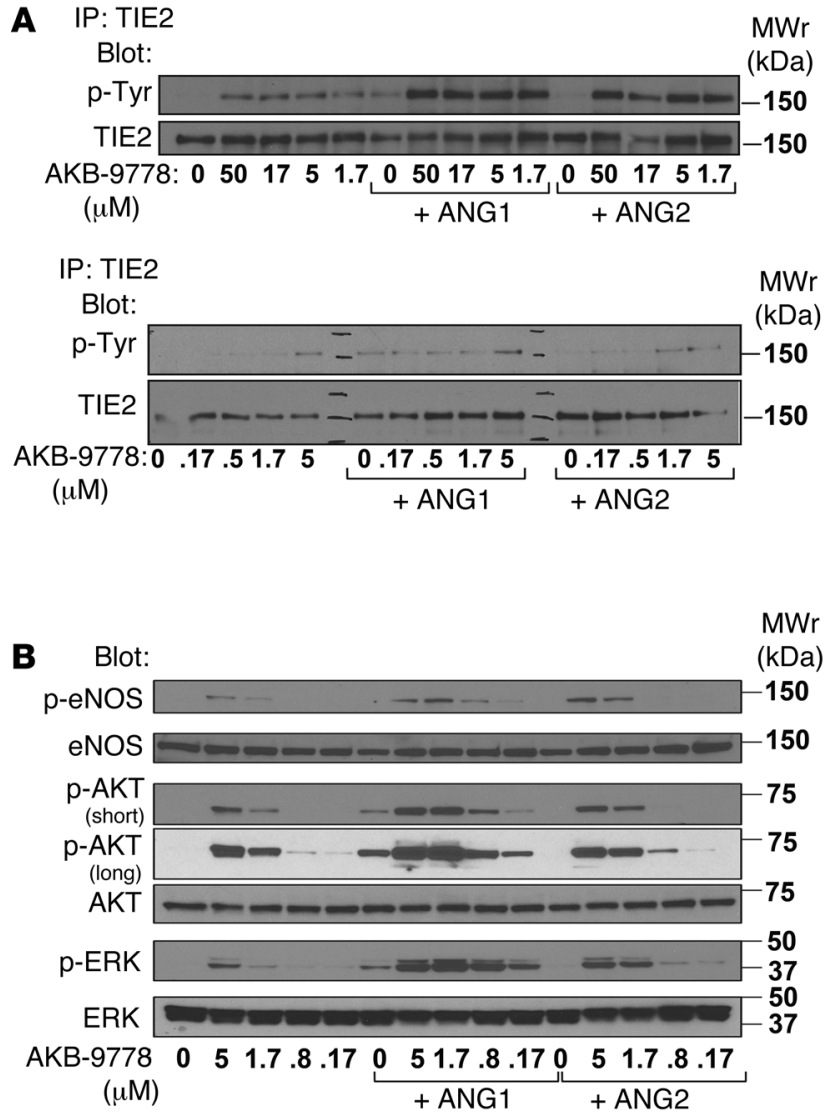

C
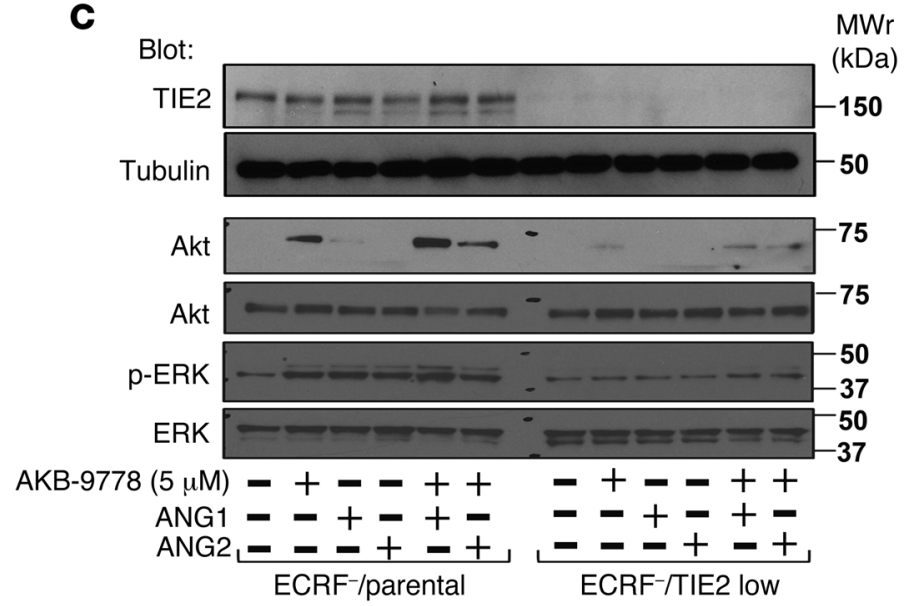

D

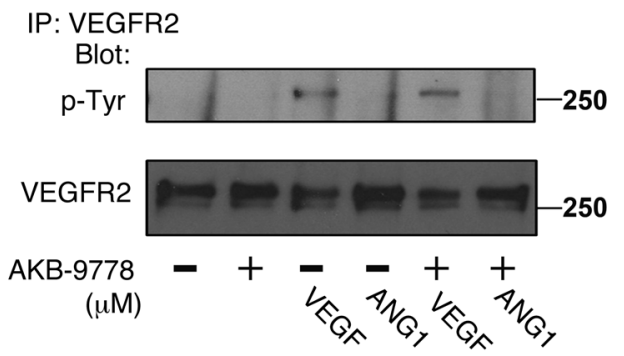

Figure 3. AKB-9778 promotes TIE2 phosphorylation and activation of downstream signaling in HUVECs and enhances angiopoietin-induced TIE2 phosphorylation. HUVECs were left untreated or were treated with AKB-9778 alone or together with ANG1 or ANG2 (500 ng/ml) for $10 \mathrm{minutes}$. Cell lysates were immunoprecipitated (IP) with anti-TIE2 and immunoblotted sequentially for phosphotyrosine ( $p$-Tyr) and TIE2, or they were probed with rabbit polyclonal antibodies against p-AKT, total AKT, p-ERK, total ERK, p-eNOS, or total eNOS. Incubation with AKB-9778 or ANG1 caused phosphorylation of TIE2 (A) and molecules in the TIE2 signaling pathway (B), which was markedly enhanced by coadministration of ANG1 with AKB-9778. Treatment with ANG2 caused no phosphorylation of TIE2 or downstream molecules, but there was strong phosphorylation with coadministration of ANC2 and AKB-9778, though less than was observed with ANG1 plus AKB-9778. (C)Knockdown of TIE2 in the EC-RF24 endothelial cell line (ECRF) with human TIE2-specific shRNA eliminated the ability of AKB-9778, with or without ANG1 or ANC2, to stimulate phosphorylation of AKT or ERK. (D) AKB-9778, ANG1, or a combination of both caused no detectable phosphorylation of VEGFR2, and AKB-9778 had no effect on phosphorylation of VEGFR2 induced by $25 \mathrm{ng} / \mathrm{ml}$ VEGF. MWr, relative molecular weight.

vessels as well as from newly formed $\mathrm{NV}$, which is visualized and quantified by immunostaining for the plasma protein albu$\min (38-40)$. At P20, when there was substantial subretinal NV, Rho-VEGF mice were treated with 3 s.c. injections of $3 \mathrm{mg} / \mathrm{kg}$ or $10 \mathrm{mg} / \mathrm{kg}$ AKB-9778 or vehicle, 12 hours apart. At P21, 2 hours after the final treatment, vehicle-treated mice showed strong staining for albumin surrounding new vessels and mild diffuse staining elsewhere (Figure 7D), while AKB-9778-treated mice showed little staining for albumin in or around the buds of subretinal NV (Figure 7E).The mean area of albumin staining per retina was significantly reduced in Rho-VEGF mice injected with $3 \mathrm{mg} / \mathrm{kg}(n=10, P=0.03)$ or $10 \mathrm{mg} / \mathrm{kg}(n=10, P=0.04)$ AKB-9778 compared with that seen in corresponding controls ( $n=8$ for each, Figure $7 \mathrm{H})$.

AKB-9778 prevents severe leakage and exudative retinal detachment in Tet-opsin-VEGF double-transgenic mice. When treated with Dox, Tet-opsin-VEGF mice express higher levels of VEGF than those seen in Rho-VEGF mice, resulting in severe NV and vascular leakage that causes exudative retinal detachments (41).
Tet-opsin-VEGF mice were pretreated for 3 days with twice-daily s.c. injections of 3,10 , or $50 \mathrm{mg} / \mathrm{kg}$ AKB- 9778 or vehicle, and then treatment was continued for 4 days during which mice were also treated with $50 \mathrm{mg} / \mathrm{kg}$ Dox to induce expression of VEGF. Extensive retinal detachments (Figure 7H, left panel) and extensive NV (Figure 7I, left panel) occurred in all mice treated with vehicle, while mice treated with $50 \mathrm{mg} / \mathrm{kg}$ AKB-9778 showed no retinal detachments (Figure 7H, right panel) and little or no NV (Figure 7I, right panel). Image analysis showed that compared with vehicle treatment, AKB-9778 treatment resulted in a dose-dependent reduction in the percentage of retinal detachment that was statistically significant in mice treated with $10 \mathrm{mg} / \mathrm{kg}$ or $50 \mathrm{mg} / \mathrm{kg}$ AKB-9778, but not in those treated with $3 \mathrm{mg} / \mathrm{kg}$ (Figure 7G).

AKB-9778 does not affect retinal vascular development. VEGF is an important stimulus for retinal vascular development as well as pathologic NV and excessive vascular leakage, and antagonism of VEGF suppresses vascularization of the retinal surface. We tested the effect of blocking VE-PTP with AKB-9778 during retinal vascular development. Compared with controls, mice treated with an 


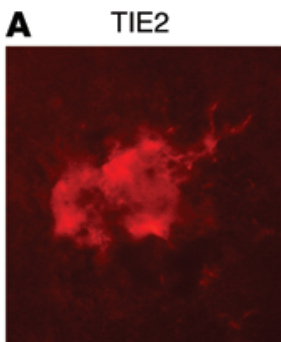

B

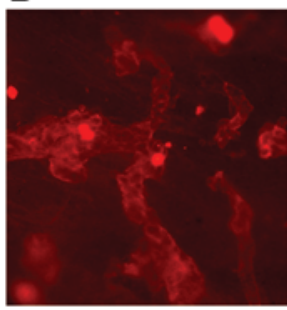

C

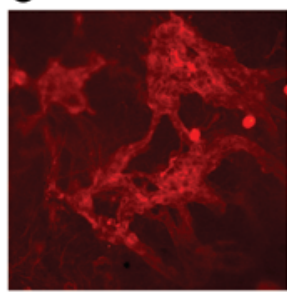

p-TIE2

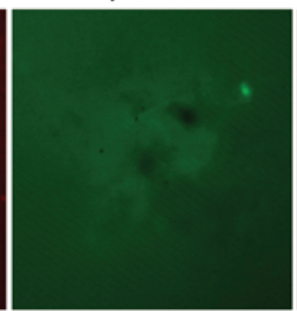

Control

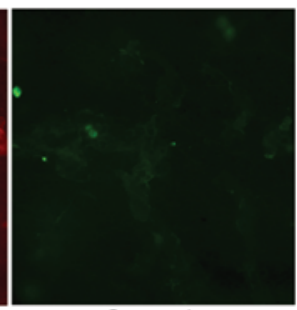

Control

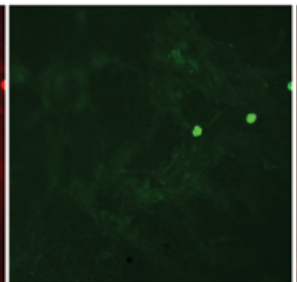

Control
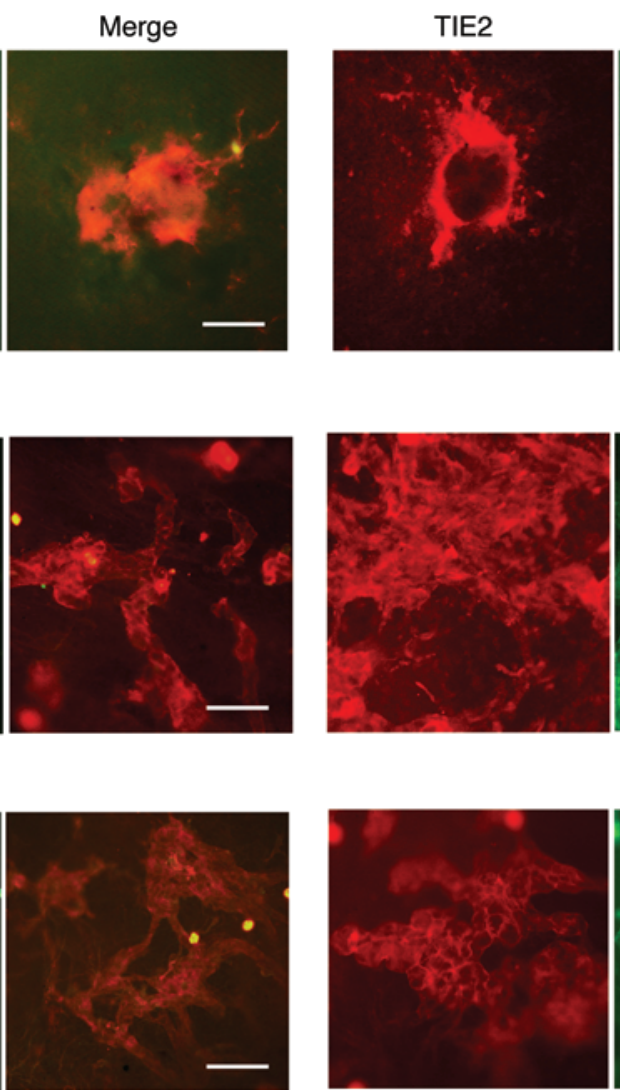

$-$
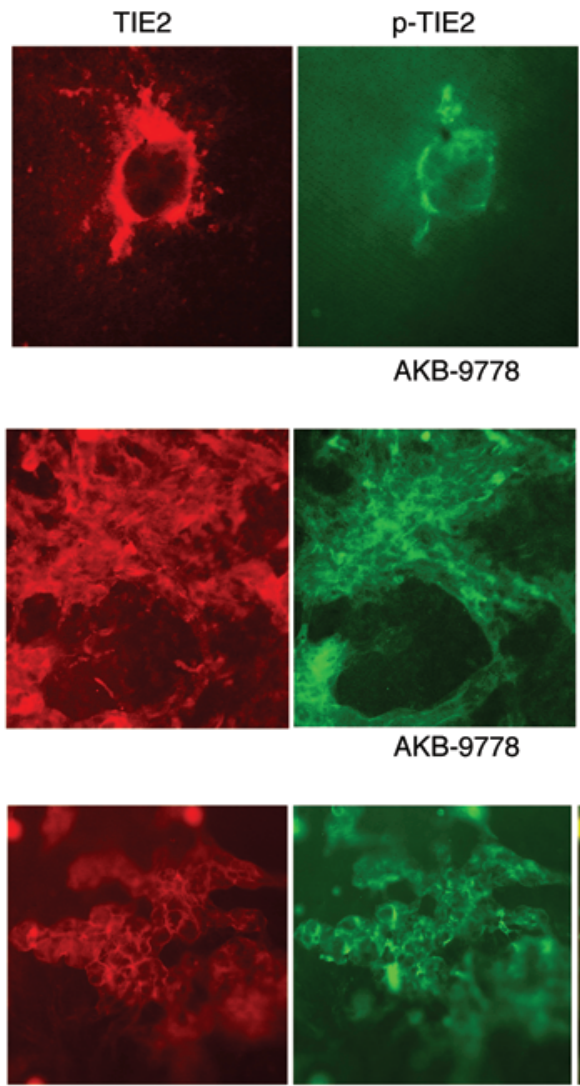

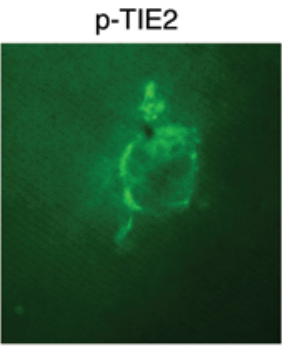

AKB-9778

AKB-9778
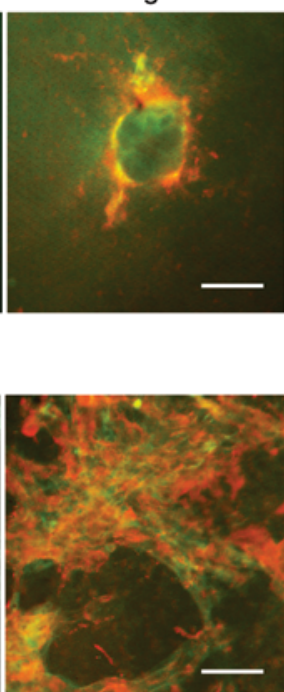

Merge
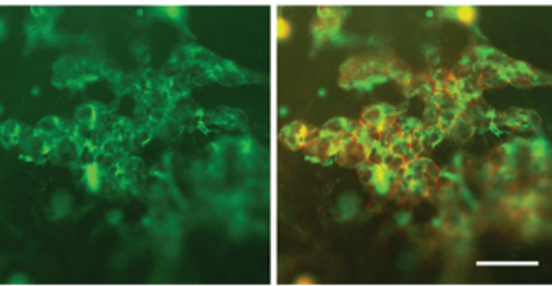

ANG1

Figure 4. AKB-9778 stimulates TIE2 phosphorylation in subretinal and retinal NV. (A) At P21, Rho-VEGF-transgenic mice were given a s.c. injection of vehicle or $20 \mathrm{mg} / \mathrm{kg}$ AKB-9778, and after 12 hours, retinal flat mounts were immunohistochemically stained for TIE2 (red) and p-TIE2 (green). In vehicle control mice, new vessels stained for TIE2, but not p-TIE2, while in AKB-9778-treated mice, they stained for both TIE2 and p-TIE2. Scale bars: $100 \mu \mathrm{m}$. (B) At P16, mice with ischemic retinopathy were administered a s.c. injection of vehicle or $20 \mathrm{mg} / \mathrm{kg}$ AKB-9778 or an intraocular injection of $500 \mathrm{ng}$ ANG1, and after 12 hours, retinas were double labeled for TIE2 (red) and p-TIE2 (green). Eyes of vehicle control mice showed extensive TIE2 ${ }^{+}$NV on the retinal surface that did not stain for p-TIE2, but in AKB-9778-treated mice, the TIE2+ NV also stained for p-TIE2. Scale bars: $100 \mu \mathrm{m}$. (C) Likewise, ischemia-induced retinal NV stained for both TIE2 and p-TIE2 after intraocular injection of $500 \mathrm{ng}$ ANG1. Scale bars: $100 \mu \mathrm{m}$.

intraocular injection of $5 \mu \mathrm{g}$ AKB-9778 at $\mathrm{P} 4$ showed no significant difference in vascularization of the retinal surface at P7 (Supplemental Figure 3).

\section{Discussion}

The TIE2 signaling pathway plays a central role in vascular homeostasis $(42,43)$. Basal stimulation of TIE2 in endothelial cells of quiescent vessels promotes a differentiated state and reduces responsiveness to $\operatorname{VEGF}(44)$. Low oxygen tension stabilizes hypoxia-inducible factor 1 (HIF-1) and causes upregulation of ANG2 and VEGF (45). By limiting TIE2 activation, ANG2 allows endothelial cells to respond to VEGF and other pro-permeability and/or mitogenic factors to facilitate new vessel sprouting $(46,47)$. In hypoxic endothelial cells in vitro or in vivo, there is upregulation of VE-PTP (Figure 2), which collaborates with ANG2 to further reduce TIE2 signaling. In some tissues, such as the heart, muscle, skin, or female reproductive tract, new vessels are productive in that they replace damaged vasculature and thereby alleviate hypoxia and promote tissue repair. The alleviation of hypoxia is accompanied by reductions in ANG2 and VE-PTP, shifting the balance back toward TIE2 activation and a return to quiescence and vascular stability. Unlike the above-mentioned tissues, NV in the retina is not productive; new vessels within or on the inner surface of the retina are disorganized and do not alleviate hypoxia, thus there is no downregulation of VEGF, ANG2, or VE-PTP. In patients with neovascular AMD, there are focal and diffuse deposits beneath the retinal pigmented epithelium (RPE), which may reduce delivery of oxygen from the choroid and also disrupt interaction of the RPE with extracellular matrix (48), resulting in upregulation of HIF-1-responsive genes and subsequent subretinal NV (49). As with retinal NV, subretinal NV does not improve hypoxia or eliminate deposits to alleviate the molecular signaling that led to NV, and without intervention, the process continues until there is destruction of the posterior retina from a large fibrovascular scar. In patients with subretinal NV, intraocular injection of a VEGF antagonist halts leakage and new vessel growth, but as the concentration of the antagonist decreases below the therapeutic level (generally within a month), leakage and/or neovascular growth resume. Thus, repeated injections of a VEGF antagonist are needed to maintain vascular stability and prevent progressive loss of vision. 
A

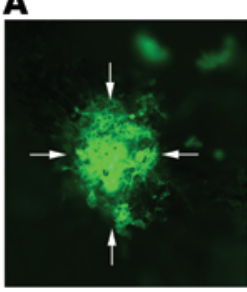

Control

C

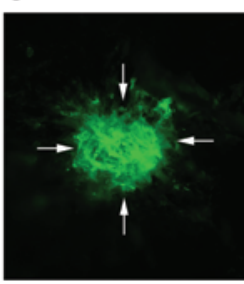

Control

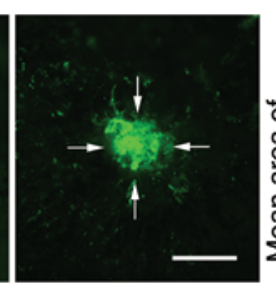

AKB-9778 $20 \mathrm{mg} / \mathrm{kg}$, bid

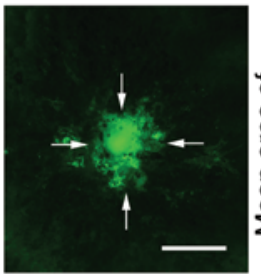

$5 \mu \mathrm{g} \mathrm{AKB}-9778$

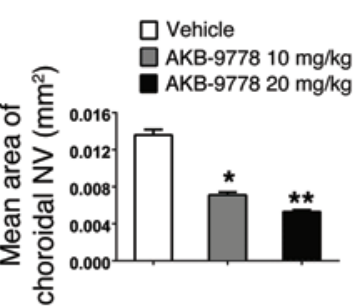

응

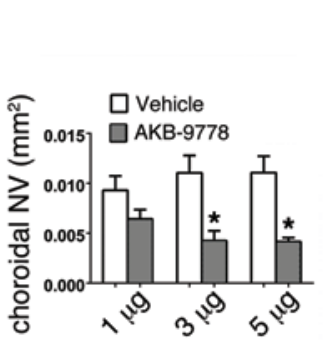

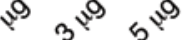

E

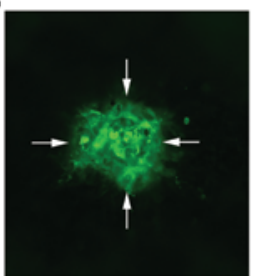

Control

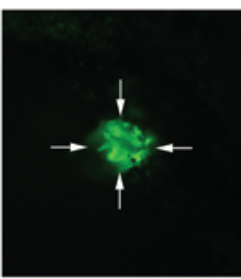

Aflibercept

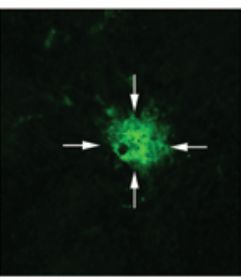

AKB-9778

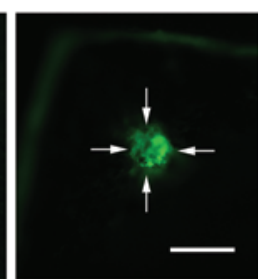

Aflibercept
B

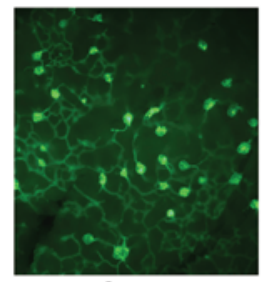

Control

D

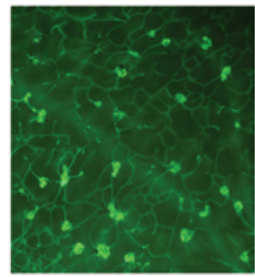

Control

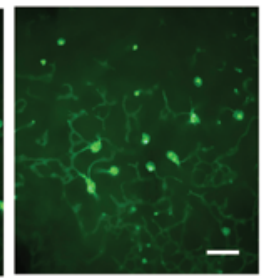

AKB-9778

$10 \mathrm{mg} / \mathrm{kg}$, bid
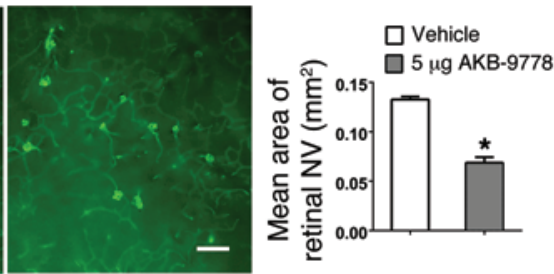

$5 \mu \mathrm{g}$ AKB-9778

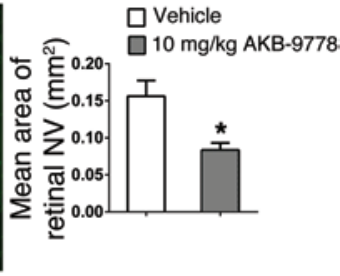

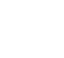

Figure 5. Subcutaneous or intraocular injection of AKB-9778 suppresses choroidal and subretinal NV. (A) Subcutaneous injection of 10 or $20 \mathrm{mg} / \mathrm{kg}$ AKB-9778 significantly reduced the area of choroidal NV $\left(n=10\right.$ for all groups in A-D; ${ }^{*} P=0.03,{ }^{* *} P=0.004$ for comparison with control by 1 -way ANOVA with Bonferroni's correction). Scale bar: $100 \mu \mathrm{m}$. (B) Subcutaneous injection of $10 \mathrm{mg} / \mathrm{kg}$ AKB-9778 significantly reduced the area of subretinal NV in Rho-VEGF-transgenic mice ( $P=0.038$ for comparison with control by unpaired $t$ test). Scale bar: $100 \mu \mathrm{m}$. (C) Intraocular injection of 3 or $5 \mu$, but not $1 \mu \mathrm{g}$, AKB-9778 significantly reduced the choroidal NV area ( ${ }^{*} P<0.01$ for comparison with vehicle control by 1-way ANOVA with Bonferroni's correction). Scale bar: $100 \mu \mathrm{m}$. (D) Intraocular injection of $5 \mu \mathrm{g}$ AKB-9778 significantly reduced the subretinal NV area in $R$ ho-VEGF-transgenic mice $\left({ }^{*} P=0.022\right.$ for difference versus vehicle control by unpaired $t$ test). Scale bar: $100 \mu \mathrm{m}$. (E) Mice had rupture of Bruch's membrane and intraocular injection of aflibercept $(40 \mu \mathrm{g})$ or PBS and s.c. injections of $20 \mathrm{mg} / \mathrm{kg}$ AKB-9778 or PBS twice daily ( $n=19$ for each of the 4 groups). After 7 days, compared with the area of GSA lectin-stained choroidal NV in the control mice, there were significant reductions in the aflibercept- and AKB-9778-treated mice $\left({ }^{*} P<0.01\right.$ by ANOVA with Dunnett's correction). Compared with mice treated with aflibercept or AKB-9778, those treated with the combination had significantly less choroidal NV ( ${ }^{*} P<0.05$ by ANOVA with Dunnett's correction). Scale bar: $100 \mu \mathrm{m}$.

An alternative to continuous VEGF blockade is stimulation of TIE2. In this study, we have used a new strategy to activate TIE2 signaling in retinal/choroidal vascular diseases. Rather than administering ANG1 to increase phosphorylation of TIE2, we have shown that the same result is obtained by inhibiting VE-PTP, a protein tyrosine phosphatase that dephosphorylates TIE2 $(25,26)$. We have done this in 2 ways: (a) intraocular administration of a previously described antibody that binds the extracellular domain of VE-PTP and (b) systemic and intraocular administration of AKB9778, a novel small-molecule inhibitor of VE-PTP catalytic activity. In hypoxic endothelial cells in vitro or in vivo, we found that VE-PTP protein was upregulated, consistent with a role for VE-PTP in the pathogenesis of ischemia-induced retinal NV. In cultured endothelial cells, AKB-9778 stimulated phosphorylation of TIE2 in the absence of exogenous ANG1 and markedly enhanced TIE2 phosphorylation and downstream signaling in the presence of
ANG1. Moreover, AKB-9778-mediated TIE2 phosphorylation was enhanced in the presence of ANG2. Thus, although ANG2 has mixed agonist/antagonist effects on TIE2, and under most circumstances the antagonist activity predominates (perhaps because it is a weak partial TIE2 agonist) (50), AKB-9778 appears to selectively accentuate its agonist activity. This finding has important implications, because in disease states complicated by NV or excessive vascular leakage, such as ischemic retinopathies, ANG2 levels are high and ANG1 levels are low $(13,51)$. While ANG1-induced TIE2 signaling was limited by hypoxia, likely due to upregulation of VE-PTP, this was not the case for AKB-9778, supporting its use as a therapeutic agent in ischemic ocular diseases.

The effects of AKB-9778 on endothelial cells in vitro were extended by investigations in several animal models. AKB-9778 suppressed retinal NV in mice with ischemic retinopathy, a model that mimics aspects of proliferative diabetic retinopathy. In that 

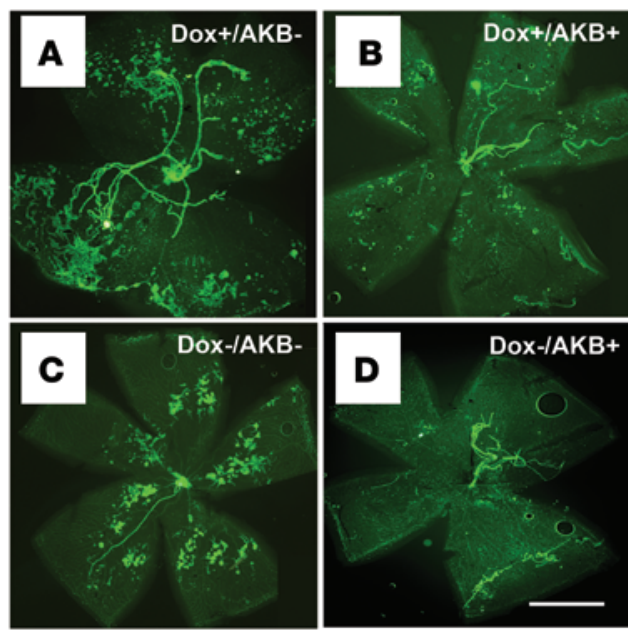

E

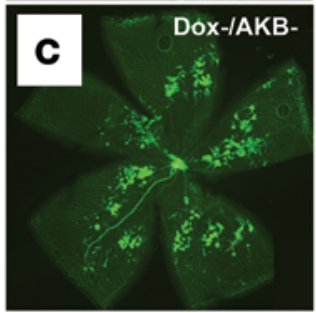

$\mathbf{F}$

G

IP: TIE2

Blot: p-Tyr
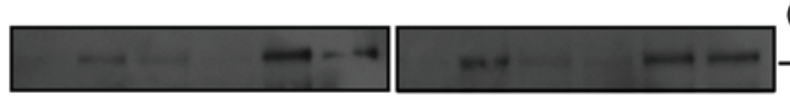

(kDa)
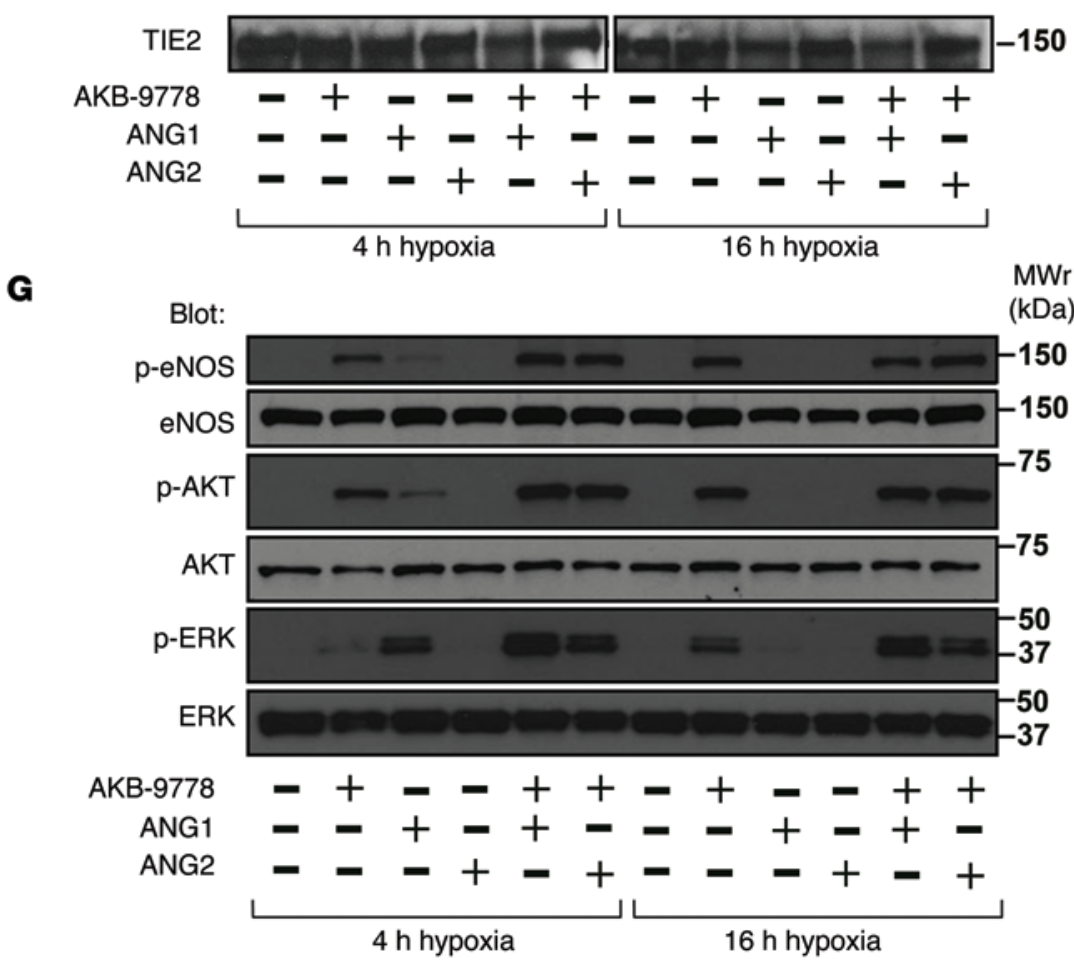

Figure 6. AKB-9778 suppresses ischemiainduced retinal NV in the presence of high ANG2 levels. Tet-opsin-Ang2 mice were placed in $75 \%$ oxygen at $\mathrm{P} 7$, returned to room air at P12, and divided into 4 groups: Dox ${ }^{+} /$vehicle $(n=17)$ received daily s.c. Dox (50 mg/kg) and an intraocular injection of vehicle; Dox $/$ AKB-9778 $(n=21)$ received daily s.c. Dox and an intraocular injection of $5 \mu \mathrm{g}$ AKB-9778; Dox $/$ vehicle $(n=10)$ received an intraocular injection of vehicle; Dox/AKB$9778(n=10)$ received an intraocular injection of $5 \mu \mathrm{g}$ AKB-9778. At P17, the Dox $/$ vehicle mice had severe NV (A) that was markedly reduced in the Dox+AKB-9778 mice (B). The large vessels are hyaloid vessels, but all other green staining is NV. Compared with Dox-/vehicle mice (C), Dox /AKB-9778 mice appeared to show less NV (D). Scale bar: $500 \mu \mathrm{m}$. The area of NV was significantly larger in $\mathrm{Dox}^{+} /$vehicle mice versus that in Dox ${ }^{-} /$vehicle mice $(\mathrm{E}){ }^{*} P<0.001$ by 1 -way ANOVA with Bonferroni's correction), indicating that ANG2 stimulated NV. The area of NV was significantly smaller in Dox $/$ AKB9778 versus $\mathrm{Dox}^{+} /$vehicle mice ${ }^{* *} P<0.001$ by 1-way ANOVA with Bonferroni's correction), indicating that AKB-9778 suppressed $\mathrm{NV}$ in the presence of high levels of ANG2 and possibly less so in the absence of high ANG2 levels. In hypoxic HUVECs (incubated in $5 \%$ oxygen for 4 or 16 hours), there were marked reductions of ANG1-induced (500 $\mathrm{ng} / \mathrm{ml}$ ) TIE2 phosphorylation (F) and downstream signaling (G); however, AKB-9778 (5 $\mu \mathrm{M})$ restored TIE2 phosphorylation (F) and downstream signaling (G), even in the presence of exogenous ANG2 $(500 \mathrm{ng} / \mathrm{ml})$. Antibodies recognizing the proteins regardless of phosphorylation status were used as loading controls. Similar results were obtained in 3 independent experiments. model, induction of ANG2 expression at the onset of the ischemic period causes a significant increase in retinal NV beyond that induced by ischemia alone (47), but treatment with AKB-9778 strongly suppressed NV despite the concomitant high expression of ANG2. This result highlights the potential benefit of ANG2-induced stimulation of TIE2 phosphorylation in the presence of AKB-9778. Treatment with AKB-9778 also suppressed subretinal NV in 2 models predictive of effects in neovascular AMD (Figure 5). The effects of AKB-9778 were additive with those obtained by intraocular injection of aflibercept, which is currently standard care in patients with neovascular AMD (Figure 5E). AKB-9778 also strongly suppressed VEGF-induced vascular leakage, which is relevant to diabetic macular edema (DME) and macular edema due to retinal vein occlusion. Similarly to the effects of ANG1 overexpression (20), injection of AKB-9778 completely prevented exudative retinal detachment in Tet-opsin-VEGF mice. This is noteworthy, because no other therapeutic agents, including intraocular injections of ranibizumab or bevacizumab (52), have such a dramatic effect in this aggressive model. As noted above, VEGF-induced vascular leakage plays an important role in DME, but it seems likely that other pro-permeability factors also participate, since VEGF antagonists are not sufficient to eliminate macular edema in many patients (53). In this regard, AKB-9778 suppressed histamine-induced permeability as well as VEGF-induced leakage from dermal vessels (Figure 7B), suggesting that its antipermeability effects are independent of the inciting stimulus and indicating that 
A

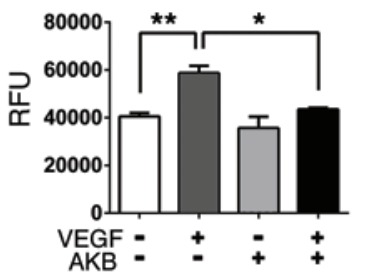

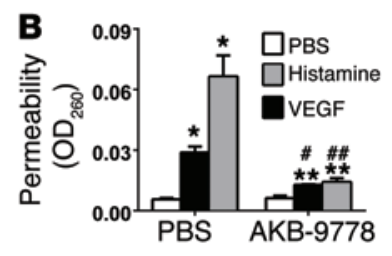
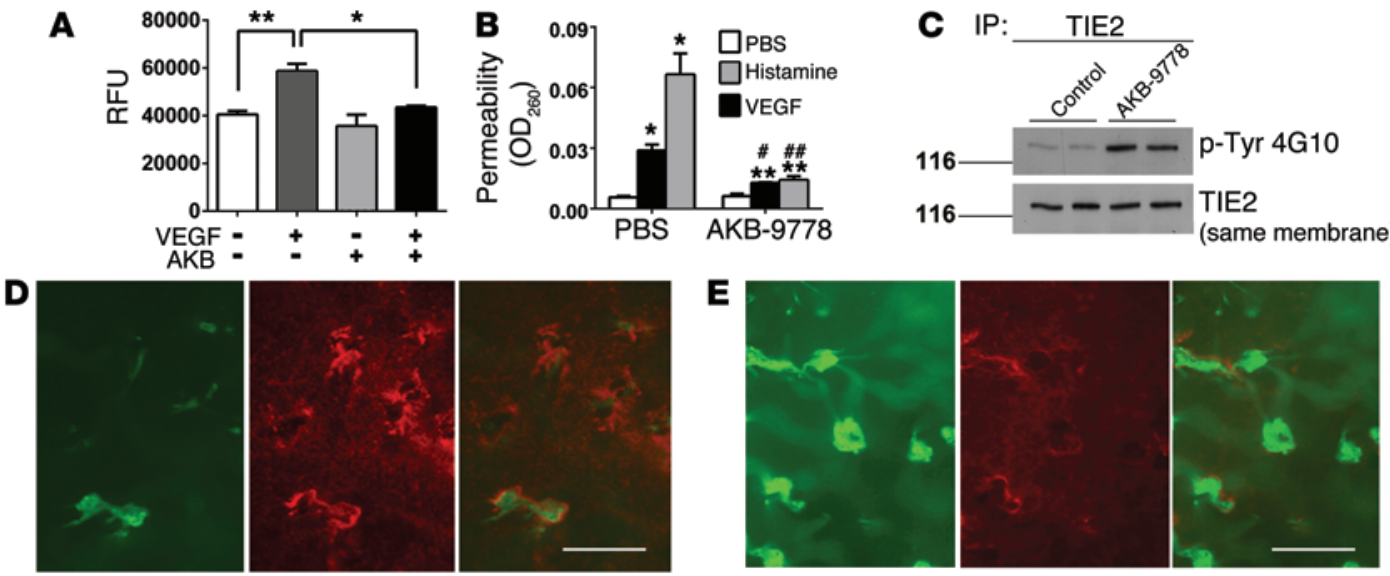

$\mathbf{F}$

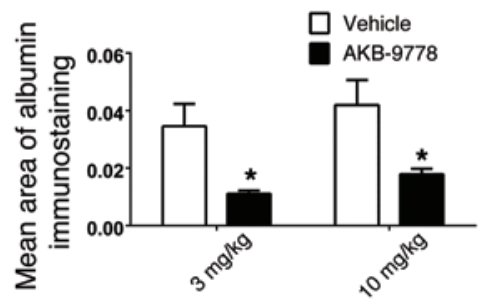

H

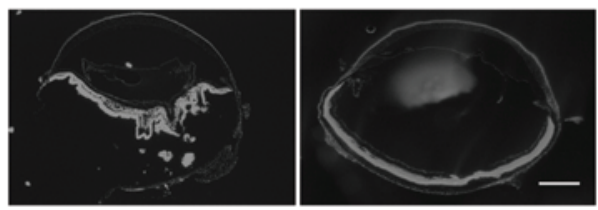

E
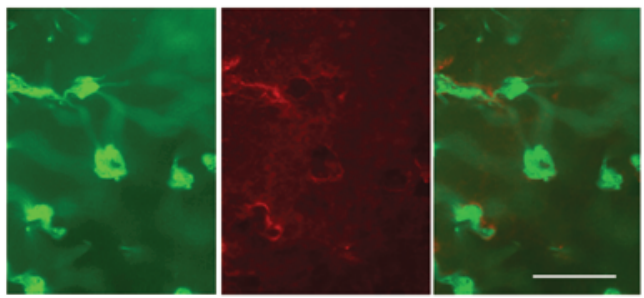

$a^{-10}$

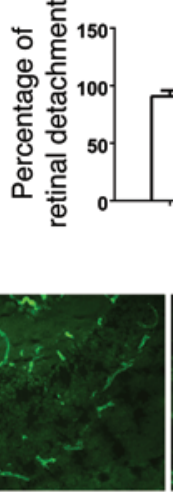

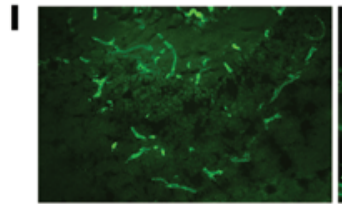

Figure 7. AKB-9778 blocks VEGF-induced permeability in HUVEC monolayers and vascular leakage in skin and retina. (A) VEGF $(200 \mathrm{ng} / \mathrm{ml})$ increased leakage of FITC-dextran ( $250 \mathrm{kDa})$ across confluent HUVECs on Transwell membranes ( $\left.{ }^{* *} P=0.005\right)$, and this was blocked by $10 \mathrm{mM} \mathrm{AKB}-9778\left(n=3 ;{ }^{*} P=0.02\right.$ by ANOVA with Bonferroni's correction). (B) Miles assay $(n=4)$ showed histamine-induced (225 ng) and VEGF-induced (100 ng) leakage of Evans blue dye $\left({ }^{*} P<0.01\right.$ vs. PBS control by ANOVA with Dunnett's correction) significantly reduced by $16 \mathrm{mg} / \mathrm{kg}$ AKB-9778 ( $P<0.01 \mathrm{vs.} \mathrm{VEGF/}$ vehicle control; ${ }^{\# \#} P<0.01$ vs. histamine/vehicle control; ${ }^{* *} P<0.05$ vs. PBS control by ANOVA with Dunnett's correction). (C) AKB-9778-treated mice showed substantially increased TIE2 phosphorylation in lung lysates. (D) Rho-VEGF mice (P20) received 3 injections of AKB-9778 ( 3 or $10 \mathrm{mg} / \mathrm{kg}$ ) or vehicle 12 hours apart, and then retinas were immunostained for albumin (red) and GSA (green). Scale bar: $100 \mu \mathrm{m}$. (E) Controls showed strong staining for albumin surrounding new vessels that caused a red haze throughout the retina, while AKB-9778-treated mice had little albumin immunoreactivity. Scale bar: $100 \mu \mathrm{m}$. (F) Mean albumin staining area per retina was significantly reduced by AKB-9778 (3 mg $/ \mathrm{kg} ; n=10$; ${ }^{*} P=0.03 ; 10 \mathrm{mg} / \mathrm{kg},{ }^{*} P=0.04$ by unpaired $t$ test) versus controls $(n=8)$. (G) Tet-opsin-VEGF mice given twice daily AKB9778 ( $n \geq 8$ /group) had a significantly lower mean percentage of retinal detachment $\left({ }^{*} P<0.0001\right.$ vs. vehicle; ${ }^{\#} P<0.001$ vs. $3 \mathrm{mg} / \mathrm{kg}$ AKB-9778 by ANOVA with Dunnett's correction). Representative sections from vehicle-treated mice showed total retinal detachment $(\mathbf{H}$, left) and extensive NV (I, left), and mice treated with $50 \mathrm{mg} / \mathrm{kg}$ AKB-9778 showed no retinal detachment (H, right) or NV (I, right). Scale bars: $500 \mu \mathrm{m}$ (H), $200 \mu \mathrm{m}$ (I). RFU, relative fluorescence units.

AKB-9778 may have advantages over selective VEGF antagonists in the treatment of DME.

In this study, we have demonstrated 2 ways of blocking VE-PTP in the eye that could potentially be translated into a treatment for retinal and choroidal vascular diseases: intraocular injection of anti-VE-PTP antibody or administration of AKB-9778, either intraocularly or systemically. Anti-VEGF treatments are given by intraocular injection, and therefore, there is precedence for the first approach, which has the advantage of limiting systemic exposure but the disadvantage of requiring frequent clinic visits and a small risk of endophthalmitis with each injection. However, neovascular AMD and DME are chronic diseases that often require repeated intraocular injections of a VEGF antagonist for many years. Subcutaneous injections of AKB-9778 could be self-administered by patients, which could reduce the burden of frequent clinic visits and the psychological burden of frequent intraocular injections along with the risk of endophthalmitis, but would require extensive testing to evaluate the safety of systemic exposure.

VE-PTP was recently established to support the adhesive activity of VE-cadherin and thereby the integrity of endothelial junctions $(54,55)$. Since this is in contrast to the effect of VE-PTP via TIE2 that we describe here, we conclude that, first, VE-PTP affects endothelial junctions via VE-cadherin and TIE2 in opposite ways; and second, the effect via TIE2 dominates the effect via VEcadherin. This implies that inhibition of VE-PTP stabilizes endothelial junctions via TIE2 by a mechanism that is independent of the direct influence of VE-PTP on VE-cadherin. Indeed, we have found that VE-PTP inhibition can even stabilize endothelial junctions in VE-cadherin $f l / f$ mice after deletion of the VE-cadherin gene (our unpublished observations). Thus, the effect that we describe here is likely to be independent of VE-cadherin. This demonstrates that there are differences between vascular development and maintenance of vascular integrity in early embryos versus $\mathrm{NV}$ and maintenance of vascular integrity in adults. Likewise, there appear to be differences regarding the role of VE-PTP in embryonic vascular development and retinal vascular development, because AKB-9778 had no effect on vascularization of the surface of the retina (Supplemental Figure 3). This raises the question of whether AKB-9778 could be used to treat retinopathy of prematurity, but much more extensive safety studies would be needed before that is considered.

Recently, it was reported that suppressing VE-PTP with AKB-9778 suppresses micrometastases in a breast cancer model (56). The demonstration that AKB-9778 promotes maturation of 
tumor vessels and reduces extravasation of tumor cells, which the authors conclude is due to bolstering of endothelial tight junctions, is consistent with our demonstration of the antipermeability effect of AKB-9778.

Collectively, retinal and choroidal vascular diseases, including neovascular AMD, proliferative diabetic retinopathy, DME, and macular edema due to retinal vein occlusions, are highly prevalent and account for the vast majority of cases of vision loss in developed countries. Although this large disease burden and its attendant high health care costs have been reduced by the development of VEGF antagonists, our data suggest that targeting the VE-PTP/ TIE2 pathway with AKB-9778 has the potential to provide substantial additional benefit in these important ocular diseases.

\section{Methods}

TIE2 signaling and permeability in cultured endothelial cells. HUVECs (57) were used before passage 6. Cells were treated for 10 minutes with AKB-9778 in the absence or presence of recombinant human VEGF, ANG1, or ANG2 (R\&D Systems). TIE2 (clone 33) (58) or VEGFR2 (clone 55B11; Cell Signaling Technology) was immunoprecipitated and probed with antiphosphotyrosine (clone 4G10), anti-TIE2, or anti-VEGFR2. Cell lysates were probed with antibodies against total and p-AKT, ERK, and eNOS (Cell Signaling Technology). Similar experiments were performed with cells maintained in $5 \%$ oxygen. VE-PTP was Western blotted with a rabbit polyclonal antibody against the $\mathrm{C}$ terminus of human VE-PTP. Changes in phosphorylation of TIE2 or downstream signaling proteins were quantified by densitometry of scanned Western blots using Image J software, version 1.47 (NIH). All experiments were repeated 3-6 times. TIE2 was silenced with a retroviral shRNA specific for human TIE2 (5'-GATCCCCCATCGAGG-3') in EC-RF24 cells (ECRF) (59). To assess permeability, HUVECs were grown on Transwell filters, pretreated with vehicle or AKB-9778 (10 mM) for 30 minutes, then PBS or human VEGF (200 ng/ml; Peprotech) was added together with $250 \mathrm{kDa}$ FITC-dextran $(0.25 \mathrm{mg} / \mathrm{ml}$; Sigma-Aldrich). FITC-dextran efflux was measured after 2.5 hours in a Synergy microplate multidetection plate reader (BioTek).

Enzyme inhibition. For $\mathrm{IC}_{50}$ determinations, compounds were diluted in assay buffer ( $50 \mathrm{mM}$ Tris- $\mathrm{HCl}, 150 \mathrm{mM} \mathrm{NaCl}, 5 \mathrm{mM}$ DTT, $1 \mathrm{mM}$ EDTA, $\pm 0.01 \% \mathrm{BSA}, \mathrm{pH} 7)$ to $7-10$ working concentrations in a 96-well plate. Following compound addition to the plate, enzyme (commercially available and P\&G-prepared proteins) was diluted in assay buffer immediately before use and delivered to the plates. Enzyme and compound were preincubated for 10 minutes at room temperature. Following preincubation, a fluorogenic phosphatase substrate, DiFMUP (6, 8-difluoro-4-methylumbelliferyl phosphate, D6567; Molecular Probes), was diluted in assay buffer immediately before use and delivered to the plates. Following addition of substrate, the plates were centrifuged briefly at $500 \mathrm{~g}$ and incubated at room temperature for 15 minutes. Following incubation, $5 \mathrm{ml}$ of a stop reagent $(50 \mathrm{mM} b \mathrm{bV}$ [phen]) was added, and the plate was read on a Victor V plate reader (PerkinElmer). Data were exported to Excel and $\mathrm{IC}_{50}$ calculations made using Excel Fit (concentration of compound that yields $50 \%$ activity).

Mouse model of oxygen-induced ischemic retinopathy. Ischemic retinopathy was produced in C57BL/6 mice or Tet-opsin-Ang2 mice (47) as previously described (27). At P12, mice were given an intraocular injection of $0.1,0.5$, or $2 \mu \mathrm{g}$ of the previously characterized anti-VE-PTP antibody (25) or $2 \mu \mathrm{g}$ IgG isotype control. In other experiments, mice were treated with intraocular or systemic AKB-9778. At P17, mice were euthanized, eyes were fixed in $10 \%$ formalin for 2 hours, and retinas were dissected intact and washed with PBS. A modification of our previously reported techniques $(60,61)$ for NV staining, flat mounting, and measurement of the retinal NV area was used. After blocking with $8 \%$ swine serum for 1 hour, retinas were stained with FITC-labeled Griffonia simplicifolia (GSA) lectin (Vector Laboratories) for 40 to 50 minutes. In previous time-course experiments, this incubation time was determined to stain retinal NV and hyaloid vessels, but not normal retinal vessels. Retinas were flat mounted, digital photographs were obtained with a Zeiss fluorescence microscope at $\times 5$ magnification, and images were merged into a single image to show the entire retina using the photomerge option of Adobe Photoshop CS5.4. ImagePro Plus software (Media Cybernetics) was used to measure the area of retinal NV per retina by an investigator blinded with respect to treatment group. Selective staining of retinal NV and hyaloid vessels greatly facilitates the measurement, because the software automatically recognizes the retinal NV and hyaloid vessels, and the hyaloid vessels are subtracted out.

Transgenic mice with increased expression of VEGF in photoreceptors. Transgenic mice in which the rhodopsin promoter drives expression of VEGF in photoreceptors (Rho-VEGF mice) have onset of VEGF expression at P7 and starting at P10, develop sprouts of NV from the deep capillary bed of the retina that grow through the photoreceptor layer and form an extensive network of new vessels in the subretinal space $(30,31)$. At P15, hemizygous Rho-VEGF mice were given an intraocular injection of 0.5 or $2 \mu \mathrm{g}$ anti-VE-PTP mAb (25) or control IgG. In other experiments, mice were given a s.c. injection of $3 \mathrm{mg} / \mathrm{kg}$ or $10 \mathrm{mg} / \mathrm{kg}$ AKB-9778 or vehicle twice a day between $\mathrm{P} 15$ and P21, or they were given an intraocular injection of $5 \mathrm{mg}$ AKB-9778 in 1 eye and vehicle in the fellow eye at P15 and P17. At P21, the mice were euthanized, and eyes were fixed in $10 \%$ formalin for 2 hours. Retinas were dissected, blocked with $5 \%$ normal swine serum in PBS for 1 hour, stained with FITC-conjugated GSA for 2 hours to stain vascular cells, flat mounted with the photoreceptor side up, and examined by fluorescence microscopy. The area of subretinal NV was measured with image analysis by an investigator blinded with respect to treatment group.

Laser-induced choroidal NV model. Choroidal NV was generated as previously described (29). Briefly, 6-week-old C57BL/6 mice had rupture of Bruch's membrane in 3 locations in each eye and were then given an intraocular injection of $0.1,0.5$, or $2 \mathrm{mg}$ anti-VE-PTP in 1 eye and $2 \mu$ g control IgG or no injection in the fellow eye, or they were given s.c. injections of 10 or $30 \mathrm{mg} / \mathrm{kg}$ AKB-9778 or vehicle twice a day for 7 days. In another experiment, mice were given an intraocular injection of $1 \mathrm{ml}$ containing 3 or $5 \mathrm{mg}$ AKB-9778 in 1 eye and vehicle in the fellow eye immediately after rupture of Bruch's membrane. In one experiment, in which the effects of AKB-9778 and aflibercept were tested alone and in combination, mice underwent laser-induced rupture of Bruch's membrane and then received an intraocular injection of $40 \mu \mathrm{g}$ of the anti-VEGF agent aflibercept or PBS and s.c. injections of $20 \mathrm{mg} / \mathrm{kg} \mathrm{AKB}-9778$ or PBS twice a day. This resulted in 4 groups of 19 mice in each group: control, aflibercept, AKB-9778, or aflibercept plus AKB-9778. Seven days after laser-induced rupture, mice were euthanized, eyecups were stained 
with FITC-labeled GSA, and choroids were flat mounted. The area of choroidal NV at each Bruch's membrane rupture site was measured using image analysis by an observer blinded with respect to treatment group. The area of choroidal NV at the 3 rupture sites in 1 eye were averaged to give 1 experimental value.

Effect of AKB-9778 on retinal vascular development. At P4, neonatal mice were given an intravitreous injection of $5 \mu \mathrm{g}(n=10)$ AKB-9778 or vehicle $(n=10)$ and were euthanized at P7. Eyes were fixed in $4 \%$ PFA for 4 hours at room temperature, and retinas were dissected and blocked with 10\% normal goat serum for 1 hour. After washing, retinas were incubated on a rocker in rat anti-mouse PECAM-1 antibody (1:150; Pharmingen) at $4^{\circ} \mathrm{C}$ overnight. After washing with PBST, retinas were incubated with goat anti-rat antibody conjugated with Alexa Fluor 488 (1:500; Invitrogen) at room temperature for 45 minutes. Retinas were washed, flat mounted, and examined by fluorescence microscopy. With the investigator blinded with regard to treatment group, image analysis was used to measure the distance from the optic nerve to the edge of the developing vasculature and to the edge of the retina in each of the 4 quadrants of the retina in the vertical and horizontal meridians. The distance to the edge of the vasculature was subtracted from the distance to the edge of the retina to give the width of avascular retina in that quadrant. The mean of the 4 measurements for each parameter was calculated to give a single experimental value per retina.

Immunostaining. At P17, mice with oxygen-induced ischemic retinopathy were euthanized, eyes were fixed in $4 \%$ paraformaldehyde for 4 hours, and retinas were removed intact. After blocking with $10 \%$ normal goat serum for 1 hour, retinas were incubated with 1:200 rabbit anti-VE-PTP for 3 hours. After washing, retinas were incubated with 1:800 goat anti-rabbit IgG conjugated with Cy-3 (Jackson ImmunoResearch Laboratories) and counterstained with FITC-labeled GSA. For p-TIE2 staining, the primary antibody used was rabbit anti-p-TIE2 (1:200; R\&D Systems), and the secondary used was goat anti-rabbit antibody conjugated with Alexa Fluor 488 (1:600; Invitrogen). For TIE2 staining, the primary antibody used was anti-mouse TIE2 (clone 33), and the secondary antibody used was goat anti-mouse conjugated with Alexa Fluor 594 (1:600; Invitrogen). Retinas were flat mounted and examined by fluorescence microscopy. At P21, Rho-VEGF-transgenic mice were given a s.c. injection of $30 \mathrm{mg} / \mathrm{kg}$ AKB-9778, and after 12 hours, retinal flat mounts were double labeled for TIE2 and p-TIE2.

Tet-opsin-VEGF double-transgenic mice. When given injections of Dox, double-transgenic mice with Dox-inducible expression of VEGF express 10-fold higher levels of VEGF than do Rho-VEGF-transgenic mice and develop severe NV and exudative retinal detachments within 3 to 5 days (41). Double-hemizygous Tet-opsin-VEGF mice were given s.c. injections of 3,10 , or $50 \mathrm{mg} / \mathrm{kg}$ AKB-9778 or vehicle twice a day. After 3 days, the mice were also administered a daily s.c. injection of $50 \mathrm{mg} / \mathrm{kg}$ Dox. After 4 days, mice were euthanized, and eyes were frozen in optimal cutting temperature embedding solution. Ten-micron ocular serial sections were cut through the entire eye, and sections 100- $\mu \mathrm{m}$ apart were stained with Hoechst (1:1,000; Sigma-Aldrich). Sections were examined by light microscopy, and the mean length of the retinal detachment per section was measured with image analysis by an investigator blinded with respect to treatment group. The percentage of the retina that was detached was computed.
Miles assay for assessment of vascular leakage in the skin. C57BL/6 mice were given an i.v. injection of $100 \mu \mathrm{l}$ \% Evans blue dye in PBS, and 10 minutes later, mice were injected intradermally at 3 sites on the back with $50 \mu \mathrm{l}$ PBS alone or with PBS containing $100 \mathrm{ng}$ mouse VEGF $_{165}$ (R\&D Systems) or $225 \mathrm{ng}$ histamine (Sigma-Aldrich). An i.v. injection of AKB-9778 (16 mg/kg in $5 \%$ dextrose- $\left.\mathrm{H}_{2} \mathrm{O}\right)$ or $5 \%$ dextrose- $\mathrm{H}_{2} \mathrm{O}$ (controls) was administered 5 hours before the assay and a second time at the beginning of the assay. Thirty minutes after intradermal injections, the mice were euthanized and the tissue at the injection site excised and extracted with $5 \mathrm{ml}$ formamide for 5 days to assess Evans blue dye extravasation. Four experiments were performed with 4 mice for each measurement. WT and DEP-1-KO mice on a C57BL/6 background (62) were preinjected i.v. with vehicle or $16 \mathrm{mg} / \mathrm{kg}$ AKB-9778, injected with Evans blue dye 30 minutes later, and analyzed as described above. Two experiments were performed with 4 mice for each measurement. For every analyzed group, 2 of the mice were analyzed for the tyrosine phosphorylation levels of TIE2 by immunoprecipitating TIE2 from lung lysates with antibody $3 G 1$ (63) and immunoblotting with $4 \mathrm{G} 10 \mathrm{mAb}$ against phosphotyrosine (EMD Millipore). DEP-1 KO was verified by immunoblotting whole lung lysates with a goat antibody against murine DEP-1 (R\&D Systems).

Immunofluorescence staining for serum albumin to assess vascular leakage. At P20, Rho-VEGF mice were given a s.c. injection of 3 or $10 \mathrm{mg} / \mathrm{kg}$ AKB-9778 or vehicle, which was repeated 12 hours later. At P21, a third injection was given, and 2 hours later, mice were euthanized and retinas dissected and immunofluorescently stained for albumin as previously described (64). The vessels were labeled by counterstaining with GSA lectin. Retinas were flat mounted, examined by fluorescence microscopy, and the area of albumin staining was measured with image analysis by an investigator blinded with respect to treatment group.

Statistics. In experiments in which a single experimental group was compared with a single control group, statistical comparisons were made by an unpaired $t$ test or a paired $t$ test when 1 eye of the mouse was in the experimental group and the fellow eye was in the control group. In experiments in which multiple experimental groups were compared with a control group or in which there were comparisons among multiple experimental groups, ANOVA with Bonferroni's or Dunnett's correction was performed for multiple comparisons. All comparisons were 2-tailed unless otherwise indicated. A $P$ value of less than 0.05 was considered significant. Data displayed in figures with error bars represent the mean \pm SEM.

Study approval. Mice were treated in accordance with the Association for Research in Vision and Ophthalmology Guidelines on the care and use of animals in research. All animal studies were approved by the IACUCs of Johns Hopkins University and Max-Planck-Institute of Molecular Biomedicine.

\section{Acknowledgments}

This study was supported by EY012609 and Wilmer Biostatistics Core Grant EY01765 from the National Eye Institute and by a grant from Aerpio Therapeutics.

Address correspondence to: Peter A. Campochiaro, The Wilmer Eye Institute, 815 Maumenee, The Johns Hopkins University School of Medicine, 600 N. Wolfe Street, Baltimore, Maryland 21287-9277, USA. Phone: 410.955.5106; E-mail:pcampo@jhmi.edu. 
1. Ferrara N, Gerber H-P, LeCouter J. The biology of VEGF and its receptors. Nat Med. 2003;9(6):669-676.

2. Ferrara $N$. Vascular endothelial growth factor: basic science and clinical progress. Endocr Rev. 2004;25(4):581-611.

3. Rosenfeld PJ, et al. Ranibizumab for neovascular age-related macular degeneration. $\mathrm{N}$ Engl J Med. 2006;355(14):1419-1431.

4. Nguyen QD, et al. Vascular endothelial growth factor is a critical stimulus for diabetic macular edema. Am JOphthalmol. 2006;142(6):961-969.

5. Campochiaro PA, et al. Ranibizumab for macular edema due to retinal vein occlusions; implication of VEGF as a critical stimulator. Mol Ther. 2008;16(4):791-799.

6. Campochiaro PA, et al. Ranibizumab for macular edema following branch retinal vein occlusion: 6-month primary endpoint results of a phase III study. Ophthalmology. 2010;117(6):1102-1112.

7. Brown DM, et al. Efficacy and safety of ranibizumab in the treatment of macular edema secondary to central retinal vein occlusion:6-month results of the phase III CRUISE study. Ophthalmology. 2010;117(6):1124-1133.

8. Nguyen QD, et al. Ranibizumab for diabetic macular edema: results from 2 phase III randomized trials: RISE and RIDE. Ophthalmology. 2012;119(4):789-801.

9. Heier JS, et al. Ranibizumab for macular edema due to retinal vein occlusions: long term follow-up in the HORIZON trial. Ophthalmology. 2012;119(4):802-809.

10. Nguyen QD, et al. Two-year outcomes of the ranibizumab for edema of the mAcula in diabetes (READ-2) study. Ophthalmology. 2010;117(11):2146-2151.

11. Campochiaro PA, et al. Long-term outcomes in patients with retinal vein occlusion treated with ranibizumab: the RETAIN study. Ophthalmology. 2014;121(1):209-219.

12. Maisonpierre PC, et al. Angiopoietin-2, a natural antagonist for Tie2 that disrupts in vivo angiogenesis. Science. 1997;277(5322):55-60.

13. Hackett SF, et al. Angiopoietin 2 expression in the retina: upregulation during physiologic and pathologic neovascularization. JCell Physiol. 2000;184(3):275-284.

14. Hackett SF, Wiegand SJ, Yancopoulos G, Campochiaro P. Angiopoietin-2 plays an important role in retinal angiogenesis. JCell Physiol. 2002;192(2):182-187.

15. Gale NW, et al. Angiopoietin-2 is required for postnatal angiogenesis and lymphatic patterning, and only the latter role is rescued by angiopoietin-1. Dev Cell. 2002;3(3):411-423.

16. Oshima $Y$, et al. Intraocular gutless adenoviral vectored VEGF stimulates anterior segment but not retinal neovascularization. JCell Physiol. 2004;199(3):399-411.

17. Oshima $Y$, et al. Different effects of angiopoietin 2 in different vascular beds in the eye; new vessels are most sensitive. FASEB J. 2005;19(8):963-965.

18. Suri C, et al. Requisite role of Angiopoietin-1, a ligand for the Tie 2 receptor, during embryonic angiogenesis. Cell.1996;87(7):1171-1180.

19. Nambu H, et al. Angiopoietin 1 inhibits ocular neovascularization and breakdown of the blood-retinal barrier. Gene Ther. 2004;11(10):865-873.

20. Nambu H, Umeda N, Kachi S, Oshima Y, Nambu $\mathrm{R}$, Campochiaro PA. Angiopoietin 1 prevents retinal detachment in an aggressive model of proliferative retinopathy, but has no effect on established neovascularization. J Cell Physiol. 2005;204(1):227-235

21. Krueger NX, Streuli M, Saito H. Structural diversity and evolution of human receptorlike protein tyrosine phosphatases. $E M B O J$. 1990;9(10):3241-3252.

22. Fachinger G, Deutsch U, Risau W. Functional interaction of vascular endothelial-protein-tyrosine phosphatase with the angiopoietin receptor Tie-2. Oncogene. 1999;18(43):5948-5953.

23. Baumer $\mathrm{S}$, et al. Vascular endothelial cell-specific phosphotyrosine phosphatase (VE-PTP) activity is required for blood vessel development. Blood. 2006;107(12):4754-4762.

24. Dominguez MG, et al. Vascular endothelial tyrosine phosphatase (VE-PTP)-null mice undergo vasculogenesis but die embryonically because of defects in angiogenesis. Proc Natl Acad Sci U S A. 2007;104(9):3243-3248.

25. Yacyshyn OK, Lai PFH, Forse K, Teichert-Kuliszewska K, Jurasz P, Stewart DJ. Tyrosine phosphatase beta regulates angiopoietin-Tie2 signaling in human endothelial cells. Angiogenesis. 2009;12(1):25-33.

26. Winderlich M, et al. VE-PTP control blood vessel development by balancing Tie-2 activity. JCell Biol. 2009;185(4):657-671.

27. Smith LEH, et al. Oxygen-induced retinopathy in the mouse. Invest Ophthalmol Vis Sci. 1994;35(1):101-111.

28. Yannuzzi LA, et al. Retinal angiomatous proliferation in age-related macular degeneration. Retina. 2001;21(5):416-434.

29. Tobe T, et al. Targeted disruption of the FGF2 gene does not prevent choroidal neovascularization in a murine model. Am J Pathol. 1998;153(5):1641-1646.

30. Okamoto N, et al. Transgenic mice with increased expression of vascular endothelial growth factor in the retina: a new model of intraretinal and subretinal neovascularization. Am J Pathol. 1997;151(1):281-291.

31. Tobe $\mathrm{T}$, et al. Evolution of neovascularization in mice with overexpression of vascular endothelial growth factor in photoreceptors. Invest Ophthalmol Vis Sci. 1998;39(1):180-188.

32. Saishin Y, et al. VEGF-TRAPR1R2 suppresses choroidal neovascularization and VEGF-induced breakdown of the blood-retinal barrier. JCell Physiol. 2003;195(2):241-248.

33. Heier JS, et al. The 1-year results of CLEAR-IT 2, a phase 2 study of vascular endothelial growth factor trap-eye dosed as needed after 12-week fixed dosing. Ophthalmology. 2011; 118(6):1098-1106

34. Klopfenstein SR, et al. 1,2,3,4-Tetrahydroisoquinolinyl sulfamic acids as phsophatase PTP1B inhibitors. Bioorg Med Chem Lett. 2006;16(6):1574-1578.

35. Evdokimov AG, et al. Engineering the catalytic domain of human protein tyrosine phosphatase $\beta$ for structure-based drug discovery. Acta Crystallogr D Biol Crystallogr. 2006;62(pt 12):1435-1445

36. Amarasinghe KKD, et al. Design and synthesis of potent, non-peptidic inhibiors of HPTP $\beta$. Bioorg Med Chem Lett. 2006;16(16):4252-4256.

37. Thurston G, et al. Leakage-resistant blood vessels in mice transgenically overexpressing angiopoietin-1. Science. 1999;286(5449):2511-2515.

38. Vinores SA, Gadegbeku C, Campochiaro PA, Green WR. Immunohistochemical localization of blood-retinal barrier breakdown in human diabetics. Am J Pathol. 1989;134(2):231-235.

39. Vinores SA, Campochiaro PA, Lee A, McGehee R, Gadegbeku C, Green WR. Localization of blood-retinal barrier breakdown in human pathologic specimens by immunohistochemical staining for albumin. Lab Invest. 1990;62(6):742-750.

40. Saishin Y, Saishin Y, Takahashi K, Melia M, Vinores SA, Campochiaro PA. Inhibition of protein kinase $\mathrm{C}$ decreases prostaglandin-induced breakdown of the blood-retinal barrier. J Cell Physiol. 2003;195(2):210-219.

41. Ohno-Matsui K, et al. Inducible expression of vascular endothelial growth factor in photoreceptors of adult mice causes severe proliferative retinopathy and retinal detachment. Am J Pathol. 2002;160(2):711-719.

42. Peters KG, et al. Functional significance of Tie2 signaling in the adult vasculature. Recent Prog Horm Res. 2004;59:51-71.

43. Augustin HG, Koh GY, Thurston G, Alitalo K. Control of vascular morphogenesis and homeostasis through the angiopoietin-Tie system. Nat Rev Mol Cell Biol. 2009;10(3):165-177.

44. Wong AL, Haroon ZA, Werner S, Dewhirst MW, Greenberg CS, Peters KG. Tie2 expression and phosphorylation in agiogenic and quiescent adult tissues. Circ Res. 1997;81(4):567-574.

45. Kelly BD, et al. Cell type-specific regulation of angiogenic growth factor gene expression and induction of angiogenesis in nonischemic tissue by a constitutively active form of hypoxia-inducible factor 1. Circ Res. 2003;93(11):1074-1081.

46. Lobov IB, Brooks PC, Lang RA. Angiopoietin-2 displays VEGF-dependent modulation of capillary structure and endothelial cell survival in vivo. Proc Natl Acad Sci US A. 2002;99(17):11205-11210.

47. Oshima Y, et al. Angiopoietin-2 enhances retinal vessel sensitivity to vascular endothelial growth factor. J Cell Physiol. 2004;199(3):412-417.

48. Mousa SA, Lorelli W, Campochiaro PA. Extracellular matrix-integrin binding modulates secretion of angiogenic growth factors by retinal pigmented epithelial cells. J Cell Biochem. 1999;74(1):135-143.

49. Vinores SA, et al. Implication of the hypoxia response element of the VEGF promoter in mouse models of retinal and choroidal neovascularization, but not retinal vascular development. JCell Physiol. 2006;206(3):749-758.

50. Yuan HT, Khankin EV, Karumanchi SA, Parikh SM. Angiopoietin 2 is a partial agonist/antagonist of Tie2 signaling in the endothelium. Mol Cell Biol. 2009;29(8):2011-2022.

51. Lip PL, et al. Plasma vascular endothelial growth factor, angiopoietin-2, and soluble angiopoietin receptor tie-2 in diabetic retinopathy: effects of 
laser photocoagulation and angiotensin receptor blockade. BrJOphthalmol. 2004; 88(12):1543-1546.

52. Miki K, Miki A, Matsuoka M, Muramatsu D, Hackett SF, Campochiaro PA. Effects of intraocular ranibizumab and bevacizumab in transgenic mice expressing human vascular endothelial growth factor. Ophthalmology. 2009;116(9):1748-1754.

53. Forooghian F, Kertes PJ, Eng KT, Agron E, Chew EY. Alterations in the intracellular cytokine milieu after intravitreal bevacizumab. Invest Ophthalmol Vis Sci. 2010;51(5):2388-2392.

54. Nottebaum AF, et al. VE-PTP maintains the endothelial barrier via plakoglobin and becomes dissociated from VE-cadherin by leukocytes and by VEGF. J Exp Med. 2008;205(12):2929-2945.

55. Broermann A, et al. Dissociation of VE-PTP from VE-cadherin is required for leukocyte extravasation and for VEGF-induced vascular permeability in vivo. J Exp Med. 2011;208(12):2393-2401. 56. Goel S, et al. Effects of vascular-endothelial protein tyrosine phosphatase inhibition on breast cancer vasculature and metastatic progression. J Natl Cancer Inst. 2013;105(16):1188-1201.

57. McClung JM, et al. Skeletal muscle-specific genetic determinants contribute to the differential strain-dependent effects of hindlimb ischemia in mice. Am J Pathol. 2012;180(5):2156-2169.

58. Niu XL, Peters KG, Kontos CD. Deletion of the carboxyl terminus of Tie2 enhances kinase activity, signaling, and function. Evidence for an autoinhibitory mechanism. J Biol Chem. 2002;277(35):31768-31773.

59. Fontijn R, et al. Maintenance of vascular endothelial cell-specific properties after immortalization with an amphotrophic replication-deficient retrovirus containing human papilloma virus 16 E6/E7 DNA. Exp. Cell Res. 1995;216(1):199-201. 60. Yoshida T, Zhang H, Iwase T, Shen J, Semenza
GL, Campochiaro PA. Digoxin inhibits retinal ischemia-induced HIF-1alpha expression and ocular neovascularization. FASEB J. 2010;24(6):1759-1767.

61. Dong A, Shen J, Zeng M, Campochiaro PA. Vascular cell adhesion molecule-1 plays a central role in the proangiogenic effects of oxidative stress. Proc Natl Acad Sci U S A. 2011;108(35):14614-14619.

62. Zhu JW, Brdicka T, Katsumoto TR, Lin J, Weiss A. Structurally distinct phosphatases CD 45 and CD148 both regulate B cell and macrophage immunoreceptor signaling. Immunity. 2008;28(2):183-196.

63. Koblizek TI, Runting AS, Stacker SA, Wilks AF, Risau W, Deutsch U. Tie2 receptor expression and phosphorylation in cultured cells and mouse tissues. Eur J Biochem. 1997;244(3):774-779.

64. Lima e Silva R, et al. Agents that bind annexin A2 suppress ocular neovascularization. J Cell Physiol. 2010;225(3):855-864. 